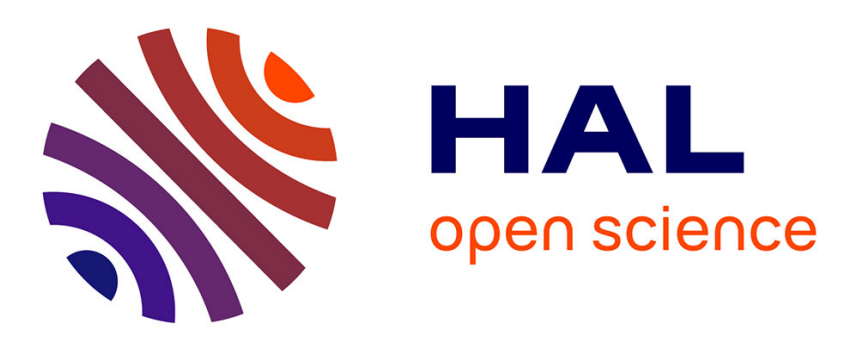

\title{
A miniature notosuchian with multicuspid teeth from the Cretaceous of Morocco
}

Jérémy Martin, France de Lapparent de Broin

\section{To cite this version:}

Jérémy Martin, France de Lapparent de Broin. A miniature notosuchian with multicuspid teeth from the Cretaceous of Morocco. Journal of Vertebrate Paleontology, 2016, 36 (6), pp.e1211534. 10.1080/02724634.2016.1211534. hal-02124147

\section{HAL Id: hal-02124147 \\ https://hal.science/hal-02124147}

Submitted on 9 May 2019

HAL is a multi-disciplinary open access archive for the deposit and dissemination of scientific research documents, whether they are published or not. The documents may come from teaching and research institutions in France or abroad, or from public or private research centers.
L'archive ouverte pluridisciplinaire HAL, est destinée au dépôt et à la diffusion de documents scientifiques de niveau recherche, publiés ou non, émanant des établissements d'enseignement et de recherche français ou étrangers, des laboratoires publics ou privés. 
A miniature notosuchian with multicuspid teeth from the Cretaceous of Morocco JEREMY E. MARTIN, ${ }^{1, *}$ and FRANCE DE LAPPARENT DE BROIN ${ }^{2}$

${ }^{1}$ Laboratoire de Géologie de Lyon: Terre, Planète, Environnement, UMR CNRS 5276 (CNRS, ENS, Université Lyon1), Ecole Normale Supérieure de Lyon, 69364 Lyon cedex 07, France, jeremy.martin@ens-lyon.fr

${ }^{2}$ Sorbonne Universités - CR2P - MNHN, CNRS, UPMC-Paris 6, Muséum national d'Histoire naturelle, 57 rue Cuvier, CP 38, 75231 Paris cedex 05, France

*Corresponding author

RH: MARTIN AND DE LAPPARENT DE BROIN—NEW CRETACEOUS NOTOSUCHIAN 
ABSTRACT - Notosuchians from Cretaceous continental environments of Gondwana have developed an unexpected array of morphological diversity comparable to mammals and their extinct relatives. However, this exceptional diversity is unbalanced with South America holding nearly three times the generic diversity of Africa-Madagascar. To the exception of the triconodonts and of a very specialized group, the Gondwanatheria, in none of these landmasses do mammals prevail and as a result, the low notosuchian diversity in AfricaMadagascar appears to be an artifact of sampling. Here, we describe a new miniature notosuchian from the Albian-Cenomanian Kem-Kem Beds of Morocco filling this gap. Lavocatchampsa sigogneaurusselli gen. et sp. nov. exhibits a new type of heterodonty with the absence of maxillary and dentary caniniform dentition and teeth that gradually become massive posteriorly, and possesses a sharp elongate median carina flanked by two multicusped cingula. The occlusion pattern is revealed by computed tomography and Scanning Electron Microscopy (SEM) and shows that the main component of jaw closure is vertical, and not horizontal as has been proposed in closely related forms. Phylogenetic results recover the new taxon as part of a basal stock of Gondwanan ziphosuchians with close affinities to Candidodon itapecuruense, Malawisuchus mwakasyungutiensis and Pakasuchus kapilimai. We revise the diagnosis of Candidodontidae, a clade characterized by a particular heterodont dentition recalling that of triconodont mammals. The recognition of this new clade confirms previous hypotheses of a vicariant vertebrate assemblage present on a continuous South American - African landmass.

\section{INTRODUCTION}

Early discoveries in Cretaceous continental outcrops of diminutive crocodylomorphs with a mammal-like dentition came as a surprise, as was notably illustrated with the case of Candidodon itapecuruense from the early Cretaceous of Brazil, initially identified as a 
mammal (Carvalho, 1994; Carvalho and Campos, 1988; Carvalho Santos et al., 2011). A comparable story is recounted when a small skull from the Cretaceous of Morocco possessing mammal-like teeth was presented to Dr. Sigogneau-Russell in 1994 for study. The skull of Lavocatchampsa sigoneaurusselli gen. et sp. nov. was first considered as a possible mammal because of the peculiar occlusal morphology (one cuspidate median carina and a cuspidate cingulum, as in molars of non-therian mammals such as triconodonts and in particular those of the Early Cretaceous of Anoual, Ksar Metlili Formation, Morocco (Sigogneau-Russell, 1995, 2003; Sigogneau-Russell et al., 1988; 1990). However, the dentition of $L$. sigoneaurusselli gen. et sp. nov. possesses a single root as in all crocodylomorphs. Since the first description of Candidodon (Carvalho, 1994) and Malawisuchus (Clark et al., 1989; Gomani, 1997) heterodont dentition including multicuspid teeth has been increasingly reported in a group of small Cretaceous crocodylomorphs, the Notosuchia, the majority of which are recorded from Gondwana (O’Connor et al., 2010) but also in one instance from Laurasia (Wu and Sues, 1996; Wu et al., 1995). These notosuchians are interpreted to be terrestrial, some having been recovered in burrows (Gomani, 1997; O'Connor et al., 2010). Such terrestrial habits provided a basis to propose vicariance as one hypothesis for the paleogeographic distribution of Gondwanan faunas during the Cretaceous (Turner, 2004). Increasing notosuchian discoveries from southern landmasses allowed Pol et al. (2014) to recognize two major radiation events, one during the Aptian, then another one during the Turonian-Santonian. The greatest diversity of notosuchians has been reported from South America with about 25 genera (see Pol et al., 2014 for an overview). Comparatively, AfricaMadagascar has yielded only five to six genera attributable to Notosuchia, but with increasing sampling efforts, we can expect at least as much discoveries as in South America due to the close proximity of both landmasses during the Cretaceous. Here, we report a new notosuchian 
from the Kem-Kem Beds of Morocco, increasing the diversity of crocodylomorphs both at the level of this geological formation and at the level of the continent.

Several crocodylomorph taxa have been reported from the Kem-Kem Beds of Morocco. These include a relatively large genus with an oreinirostral skull, Hamadasuchus rebouli Buffetaut, 1994 now represented by relatively complete skulls (Rauhut and LópezArbarello, 2005; Larsson and Sues, 2007), to which a skull table assigned to Libycosuchus sp. by Buffetaut (1976) has recently been reassigned by Larsson and Sues (2007). Besides, Larsson and Sidor (1999) assigned some isolated teeth from the Kem-Kem Beds to indeterminate notosuchians and more recently, Sereno and Larsson (2009) reported a new genus of Araripesuchus, A. rattoides on the basis of dentary bones. The Kem-Kem Beds of Morocco also produced remains of the elosuchid Elosuchus cherifiensis (Lavocat, 1955) (de Lapparent de Broin 2002c) as well as Laganosuchus maghrebensis, a genus also recovered from the Cenomanian of Niger and possibly related to Stomatosuchus inermis Stromer, 1925 from the Cenomanian Baharija Formation of Egypt (Sereno and Larsson, 2009).

The aim of this work is to describe the remarkable derived morphology of the new notosuchian Lavocatchampsa sigoneaurusselli gen. et sp. nov. from the Kem-Kem Beds of Morocco, test its affinities with other notosuchians and discuss its ecological and paleobiogeographical relevance.

Institutional Abbreviations - MNHN F, Muséum National d'Histoire Naturelle, Paris, Paléontologie.

\section{PROVENANCE AND GEOLOGICAL SETTING}

\section{Provenance}

Lavocatchampsa sigoneaurusselli gen. et sp. nov. was excavated in the locality of OuedTal, Morocco, on the northern foot of the cliff delimiting the Morocco-Algerian border. East of 
Erfoud, OuedTal is located east of the intermittent Oued Talrheml that flows from the north. The locality of OuedTal belongs to the Kem-Kem Beds Formation (Sereno et al., 1996), which extensively crops out in southeast Morocco, close to the Morocco-Algerian border. It forms the northeastern limit of the Anti Atlas Mountains, at their northern reach with the High Atlas. The formation is part of the Errachidia (former Ksar Es-Souk) province (MeknesTafilalet administrative Region) and of the Agora province (Souss-Massa-Drâa Region, with Tagounit municipality) (Fig. 1). It is an area of high plateaus, the Hamadas, covered by a limestone cap where tectonic deformations and erosion induced the formation of oueds, valleys, cliffs, butte temoins and crests.

\section{Geological Setting}

The continental Kem-Kem Beds of Sereno et al. (1996), part of the Infracenomanian of Clariond (1933), constitute the uppermost western part of a larger formation, the "Continental Intercalaire (du Sahara)" (Kilian 1931; Furon 1955; Choubert, 1956; Le Loeuff et al., 2012), which includes individually geologically separable formations according to the countries. The whole continental Intercalaire Formation extends across North Africa from east to west, with Paleozoic and Mesozoic sediments, the latter comprising a succession ending up with the marine Cenomano-Turonian and reaching a thickness of up to $500 \mathrm{~m}$ when Paleozoic continental layers are present (Lavocat, 1954; Taquet, 1976; Busson and Cornée, 1995).

The Saharian Upper "Continental Intercalaire" part can be considered into two superimposed units. The upper part is attributed to the late Albian - early Cenomanian, prior to the great Cenomano-Turonian transgression (Furon, 1955; Choubert, 1956; Lavocat, 1954; Taquet and Russell, 1998), but it can eventually be reduced to the Cenomanian part or to the Albian one in northern African places. It is preserved in the Kem-Kem Beds, in discontinuity over peneplanized Carboniferous layers in the studied area, without the underlying lower Cretaceous part of the Upper "Continental Intercalaire”, elsewhere known by early 
Cretaceous Formations in Algeria, Niger and Tunisia. In the Kem-Kem Beds, the Upper "Continental Intercalaire" part includes faunas known either in Cenomanian layers or in Albian layers or in undistinguished Albian-Cenomanian layers (fishes, crocodylomorphs, dinosaurs, turtles) (Bellion et al., 1992; de Broin, 1965; Bouaziz et al., 1988; Buffetaut, 2001; Buffetaut et al., 1990; Busson and Cornée, 1995; de Lapparent, 1951; de Lapparent, 1960; de Lapparent de Broin, 2000a,b; Lavocat, 1948; Lavocat, 1954; Mahler, 2005; Mateer et al., 1992; Taquet, 1976).

The Kem-Kem Beds of Morocco are themselves composed of two superimposed continental units of red color, with a principally detritic, arenaceous sandstone layer below and above an intercalation of sandstone and clay layers in continuity with the overlying Cenomanian cap, itself eventually covered by sediments including more or less Upper Cretaceous and Tertiary to Pleistocene sediments, depending on the area (Lavocat, 1954). The Kem-Kem Beds are visible in the steep slopes of the Hamada cliffs generally outcroping below the hard Cenomano-Turonian marine limestone cap, and in the holes excavated by fossil "hunters" in the cliffs and at the foot of the cliffs in the valley, such as the locality of Lavocatchampsa sigoneaurusselli gen. et sp. nov. The thickness of these upper continental sediments varies from ca. $25 \mathrm{~m}$ up to $200 \mathrm{~m}$. The precise extraction level of $L$. sigoneaurusselli in the Kem-Kem Beds series is unknown, but possibly from the lower levels as suggested by the presence of an excavated hole at the foot of the cliff (Fig. 1).

As far as the crocodylomorphs are concerned, the Aptian level of the earliest part of the Saharian "Continental Intercalaire" is notably characterized in Northern Africa by the presence of the giant Sarcosuchus imperator de Broin and Taquet, 1966: Gadoufaoua (Southeastern Ténéré) in Niger; Aoulef (Tikidelt, North of Hoggar) in Algeria; at the LibyaTunisia boundary (Gara Kamboute area in Tunisia (de Lapparent 1960; de Broin, 1965; de 
Broin and Taquet, 1966; de Lapparent de Broin, 2000a,b; Prasad and de Lapparent de Broin, 2002; Sereno and Larsson, 2009); Cabao Formation in Libya (Le Loeuff et al., 2010)).

On the other hand, the late Albian-early Cenomanian part of the Saharian "Continental Intercalaire" yielded Elosuchus, de Lapparent de Broin, 2002c, being present in the Kem-Kem Beds of Morocco (where it has been sometimes confused with Sarcosuchus); Oued Boudjihane (Bassoulet and Iliou, 1967) and Gara Samani (and probably In Akhamil) in Algeria; In Abangarit (Tamesna, South of Hoggar) in Niger (de Broin, 1965; de Broin et al., 1971; de Lapparent de Broin, 2002; Lavocat, 1955), Sudan (Werner, 1995; Werner and Rage, 1994) and Ethiopia (Schmidt and Werner, 1998; Werner, 1995). The genus Elosuchus has never been reported in Baharija (Egypt), a Cenomanian locality that yielded other crocodylomorph taxa, i.e. Stomatosuchidae (Stromer, 1933; Sereno and Larsson, 2009), eventually related to the most recent forms of the Continental Intercalaire.

The Kem-Kem Beds supplied a great amount of other continental fossil vertebrates below the marine Cenomano-Turonian cap including fishes, frogs, squamates, turtles, crocodylomorphs (see Introduction), dinosaurs, pterosaurs, as well as invertebrates and plants (see review in Cavin et al., 2010). These species or genera of the Kem-Kem fauna are found in the upper part of the Upper "Continental Intercalaire" of Sahara in correlated places with Morocco in Egypt, Tunisia, Algeria, Sudan and Niger (see review in Cavin et al., 2010 and Choubert, 1956; Dutheil, 2000; Furon, 1955; de Lapparent de Broin, 2000a, b; Larsson and Gado, 2000; Werner, 1995; Werner and Rage, 1994). Among this fauna, vertebrate remains from the Kem-Kem Beds are either found in Kem-Kem sensu stricto or in Guir Hamada localities where the fauna is richer.

\section{MATERIAL AND METHODS}


Computed Tomography - The cranial remains of Lavocatchampsa sigogneaurusselli gen. et sp. nov. were scanned on a Phoenix X-ray computed tomography scanner at École Normale Supérieure de Lyon, France. The rostrum including the mandible was scanned at a slice resolution of $18 \mu \mathrm{m}$; the two separated $7^{\text {th }}$ and $8^{\text {th }}$ dentary teeth were scanned at a slice resolution of $5.5 \mu \mathrm{m}$ for a voltage of $100 \mathrm{kV}$ and an intensity of $70 \mu \mathrm{A}$. Volume rendering and processing of scans were completed under the software VG Studio max 1.0.

Microwear analysis - Fine details of the crown surface of the right $7^{\text {th }}$ and $8^{\text {th }}$ dentary teeth of Lavocatchampsa sigogneaurusselli gen. et sp. nov. were examined under a scanning electron microscope (SEM). This study was conducted in the Muséum National d'Histoire Naturelle, Paris, Laboratory of Paleontology, with a magnification of 15 to 450 .

\section{SYSTEMATIC PALEONTOLOGY}

SUPERORDER CROCODYLOMORPHA Walker, 1970

ORDER CROCODILIA Gmelin, 1789 sensu Martin and Benton, 2008

SUBORDER MESOEUCROCODYLIA Whetstone and Whybrow, 1983 INFRAORDER NOTOSUCHIA Gasparini, 1971

TAXON ZIPHOSUCHIA Ortega, Gasparini, Buscalioni and Calvo, 2000 FAMILY CANDIDODONTIDAE Carvalho, Ribeiro and Avilla, 2004

Revised diagnosis - The following diagnosis is built on comparison with other notosuchians from the literature and from the results of the phylogenetic analysis (unambiguous synapomorphy indicated with *): small size notosuchians $(<60 \mathrm{~cm}$ in total body length) with a short and triangular rostrum, possessing a dentition with complex crowns superficially resembling molariform mammalian teeth and sharing the following characters: small number of teeth (5 to 7 per maxilla) (character 108); relatively large molariforms; cingulum always 
present but relatively variable in extension around the crown (character $390^{*}$ ); the cingulum bears a variable number of more or less acute cuspids (cuspids absent in Pakasuchus); the cingulum encircles the median carina; the median carina makes the apex of the crown and has a variable mesiodistal length and can consist of a single, two or three cusps depending on the tooth position in the jaw (Candidodon, Malawisuchus, Lavocatchampsa) (character 188). The median carina can also consist of a double crest divided by a longitudinal groove (Pakasuchus).

Content-Family including the genera Candidodon, Lavocatchampsa, Malawisuchus and Pakasuchus.

Distribution - Gondwana (Africa, South America), Early Cretaceous up to Early Cenomanian included.

LAVOCATCHAMPSA SIGOGNEAURUSSELLI gen. et sp. nov.

(Figs. 2-9)

Etymology - The genus name honors the memory of the French paleontologist René Lavocat (1909-2007) for his contribution to vertebrate paleontology in Africa and in particular for the exploration of the Kem-Kem Beds and the discovery of its vertebrate fossil fauna. The specific name honors Dr Denise Sigogneau-Russell, specialist of early mammals and at the origin, with her husband Dr Donald Russell, of the acquisition of the specimen from Bruno Fectay.

Holotype-MNHN F MRS 2097, anterior portion of a rostrum with mandible in occlusion with an almost complete dentition. 
Locality and Horizon — OuedTal, East of Erfoud, Errachidia Province (Meknes-Tafilalet administrative Region) is part of a sequence of continental deposits, situated east and along the Moroccan-Algerian border in the northwestern part of the Guir Hamada, Morocco. KemKem Beds, Late Albian-Early Cenomanian. GPS coordinates of the locality are available with the curated specimen.

Diagnosis - Lavocatchampsa sigogneaurusselli gen. et sp. nov. is a small notosuchian crocodylomorph with a lightly sculptured oreinirostral skull that possesses the following unique combination of characters (autapomorphies denoted with *): presence of antorbital fossa/fenestra; broadly concave dentary tooth row in lateral view*; extensive mandibular symphysis incorporating about half of the total splenial length; seven maxillary and nine dentary alveoli; absence of caniniform teeth on the maxilla*; heterodont maxillary and dentary dentition with progressively mesiodistal elongation of roots and crowns posteriorly and progressive development of a labial and lingual cingulum from anterior dentition to posterior dentition; edge of cingulum with numerous triangular, rounded at the summit and closely spaced accessory cusps (increasing number up to ca. 20 or more on teeth 7 and 8 ); tooth crown with progressively expanding mesiodistal blade (median carina) consisting of two cusps in anterior subconical teeth, then three cusps from maxillary tooth 5 and dentary tooth $5^{*}$; caudal tip of nasals separated by an anterior acute sagittal projection of frontals; triconodont tooth morphology as in Candidodon, Malawisuchus and Pakasuchus but distinguished by the shape of the cuspids of the median carina(e) and the high number of tubercles on the cingulum(a).

\section{DESCRIPTION}

\section{General description}

Lavocatchampsa sigogneaurusselli gen. et sp. nov. is represented by a single specimen, which consists of a rostrum with mandibles in occlusion and associated dentition. The total length of 
the preserved portion measures $38.5 \mathrm{~mm}$. The preserved portion of the rostrum extends from the anterior tip of the mandible to the anterior margin of the orbits. Preserved bones of the rostrum include the maxillae, nasals, left jugal, left lacrimal, parts of the prefrontal and frontal, left anterior portion of the ectopterygoid and the anterior extent of the palatine. The specimen experienced some crushing on the dorsal surface of the rostrum. The external nares are not discernible and the lateral sides of the premaxillary and maxillary tooth rows are eroded, revealing the roots of the maxillary dentition. The mandibles are nicely preserved but incomplete, missing the posteriorly placed bones corresponding to the angulars and articulars and most part of the surangulars. The dentaries and splenials are nearly complete and the anteriormost tip of the left surangular is preserved. The skull and lower jaw were digitally separated allowing observations of their palatal surfaces.

\section{Skull and mandible}

Premaxilla - The premaxilla is missing although a single damaged premaxillary tooth seems to be preserved just anterior to the narial opening. The external nares are possibly preserved but their outline is difficult to follow due to the collapse of the surrounding bones.

Nasal-The nasals are visible in dorsal view and have the shape of a long rectangular bone with a flat surface. They are damaged and the left nasal has collapsed in the rostrum. Their dorsal surface is feebly ornamented with longitudinal grooves. The nasals seem to contribute to the posterior margin of the external nares but the identification of the premaxillae in this area is uncertain and what could be the external nares might also correspond to the collapsed narial passage passing below the nasals.

Maxilla - The external surface of the maxillae is mostly eroded with the exception of the posterolateral left surface. The lateral surface of the maxillae is vertical. The maxillae meet medially on the palate. Here the palate is fully closed, no palatal fenestra could be detected. In 
cross section, the palatal ramus of the maxilla is concave. The external surface of the maxillae adjacent to the last three maxillary alveoli is thick (Fig. 3F). Here, ornamentation consists of small circular and spaced pits. The left maxillary tooth row is complete and hosts seven alveoli with teeth, which gradually increase in size posteriorly. Only the last three left maxillary alveoli of the left row are complete, the anteriormost alveoli having their external surface eroded. Although a thin lamina emerges from the labial and lingual alveolar walls, these alveoli are confluent. The right maxillary tooth row has five alveoli preserved with teeth (second to sixth teeth), the external and most of the dorsal maxillary wall being eroded.

Lacrimal - Lateral to the nasal on the left side of the skull, a small part of superficially smooth bone (Fig. 3B) corresponds to the lacrimal. In lateral view, the lacrimal surface hosts a concavity, which represents the upper margin of the antorbital fossa (Figs. 3B, 4B). The left lacrimal is preserved in two parts with the most anterior part being displaced anteriorly. This is supported by a foramen revealed on the two sectioned elements (Fig. 3B).

Frontal-The frontal is represented by its anteriormost process, which is unpaired. Here, the frontal wedges between the posteriormost processes of the nasals (Fig. 2A).

Ectopterygoid - The left ectopterygoid is visible in dorsal and palatal views. Only its anterior ramus is preserved and contributes to the posteriormost margin of the last maxillary alveolus. The ectopterygoid does not contribute to the medial wall of the maxillary tooth row. Laterally, it contacts the anteroventral process of the jugal. A portion of the left suborbital fenestra is preserved, just anterior to the ectopterygoid. Here, the anterolateral corner of the suborbital fenestra is bordered by the maxilla.

Palatine - The anterior tip of the palatines is preserved and separates the posterior interdigitated suture of the maxillae (Fig. 3F). The palatine reaches the level of the fifth/sixth maxillary alveolus. The anteriormost portion of the right choanal septum is preserved (Figs. $3 \mathrm{~F}, 4 \mathrm{~F})$ and indicates that the choanae were penetrating far anteriorly in the palatine as in 
Araripesuchus patagonicus Ortega et al., 2000. The anteriormost tip of the jugal reaches the level of $7^{\text {th }}$ maxillary alveolus.

Dentary - In ventral view, the dentaries form an anteriorly pointed triangle. The bestpreserved dentary is the left, which misses only some of its posteroventral and posterolateral portions. Ornamentation consists of small circular pits separated by wide grooves distantly placed on the ventral and lateral surface of the dentary. The dentary contains a maximum of nine alveoli as observed from the left side, which is complete. The longest alveolus is the seventh, from which the last two alveoli progressively decrease in mesiodistal length. In occlusal view, the anteriormost tip of the tooth row has a U-shaped profile and the rest of the tooth row is nearly parallel to its counterpart except in its posteriormost end where it slightly diverges laterally. In lateral view, the dentary has the distinct curvature of a spoon: from the tip of the dentary to its posterior end, the dorsal surface has a single markedly concave profile, which fits with the convex posterior margin of the maxilla, as seen on the left side of the skull (Fig. 3B). The anterolateral margin of the dentary adjacent to the tooth row is continuous with the ventral margin of the dentary. But from the level of the fifth dentary alveolus until the last alveolus, the lateral surface of the dentary consists of a shelf that gradually expands posteriorly. Both dentaries meet along an extended symphysis, which ends at the level of the alveolar border between the fifth and sixth alveoli. In cross section, the occlusal surface of the dentary symphysis is not flat but $\mathrm{V}$-shaped. Numerous foraminae are found adjacent to the lingual margin of the tooth row.

Splenial-The left splenial is nearly complete, missing its posteriormost part (Figs. 3G, H). The splenial has a deep triangular participation in the mandibular symphysis and reaches between the level of the fifth and sixth dentary alveoli. The splenial contributes to the entire lingual wall of alveoli 7 to 9 . Lingual to alveoli 7 and 9 , the splenial is thick and convex giving to the posterior end of the mandible a sigmoid shape in occlusal view. In ventral view, 
the anterior tip of the splenial is covered by a thin lamina of the dentary, which is damaged on the right side and nearly complete on the left side.

Surangular-Only the anteriormost tip of the left surangular is preserved (Figs. 3B, H). It consists of a single lamina that overlaps the dentary but does not reach the level of the posteriormost dentary alveoli. The anterior process of the surangular is not forked but has a rounded anterior end.

\section{Dentition}

Observations were made from an external view as well as from the CT scan (Figs 2, 3, 5-8). A single heavily altered right premaxillary tooth is present but no other information could be gained. The dental formula is $(7 \mathrm{mx} / 9 \mathrm{den})$. All teeth described here are multicusped and the type of heterodonty varies from a subconical morphotype to an enlarged molariform morphotype. All teeth bear a cingulum, of which the morphology and number of cusps vary along the tooth row. The cingulum bears small and rather numerous cuspids arranged all around the tooth crown.

Maxillary teeth - The first maxillary tooth is visible on both sides of the skull as indicated by the presence of damaged roots only (Figs. 3-5). The second maxillary tooth is seen from both sides of the skull. Taken from the left side, its height including the cusp and root is $5.9 \mathrm{~mm}$ and the crown has a maximum mesiodistal length of $1.6 \mathrm{~mm}$, a labiolingual width of $1.4 \mathrm{~mm}$ and a height of $2 \mathrm{~mm}$. The crown-root junction is constricted. The apex of the crown consists of two cusps, the mesial cusp being taller than the distal one (Fig. 5C, D). The mesiolabial corner of the left crown is damaged but that of the right crown is complete and shows no evidence of a cingulum. In both the right and left teeth, the distolabial corner of the crown 
presents at its base a cingulum with two small accessory cusps on its edge (Fig. 5C). In lingual view, an accessory cusp is visible at the base of the crown but a cingulum is absent.

The third maxillary tooth is overall similar to the second one but its root and crown are longer. The crown has a mesiodistal length of $2.6 \mathrm{~mm}$, a labiolingual width of $1.6 \mathrm{~mm}$ and a maximum height of $1.8 \mathrm{~mm}$. The total height of the tooth including the crown is about $6 \mathrm{~mm}$. The apex of the crown also consists of two cusps, the mesial one being taller than the distal cusp (Fig. 5C). No cingulum is present on the lingual base of the crown but contrary to the second maxillary tooth, a cingulum extends along the entire base on the labial side of the crown (Fig. 5C, D). Eight accessory cusps are present on the edge of this cingulum and are best seen on the right tooth.

The fourth maxillary tooth is best represented on the right (Fig. 5C, D), which is less damaged than the left one. The crown has substantially larger dimensions with a mesiodistal length of $3.8 \mathrm{~mm}$, a labiolingual width of $2.5 \mathrm{~mm}$ and a height of $2.4 \mathrm{~mm}$. The crown consists of a large mesial cusp and a distal cusp is revealed by the concavity visible on the lingual side of the crown, as in maxillary teeth 2 and 3. However, the distal cusp is not prominent here. The cingulum extends along the entire labial side of the crown but a total count of its accessory cusps cannot be given because the anterior region of the cingulum is damaged. In the posterior region of the cingulum at least 8 accessory cusps are present. A hint of a cingulum is detected on the anterior region of the lingual side of the fourth maxillary tooth (Fig. 5D).

The fifth maxillary tooth is best preserved on the right side (Fig. 5A, B). The crown is even larger than the fourth tooth with a mesiodistal length of $4.7 \mathrm{~mm}$, a labiolingual width of $3.3 \mathrm{~mm}$ and a height of $3.7 \mathrm{~mm}$. The tooth including the root and crown is $7.5 \mathrm{~mm}$ in height. In occlusal view, the crown is ovoid and is divided in half by a mesiodistal carina (median carina) (Fig. 5B). In labial view, this carina is composed of the central cusp and two smaller 
cusps aligned mesially and distally to the central cusp. The mesialmost cusp is detectable but is less individualized than the distal cusp. The median carina is flanked at its base by a labial as well as a lingual cingulum. Both cingula run for the entire length of the crown. The labial cingulum possesses at least 15 accessory cusps on its edge, which become smaller and closer to each other toward the mesial edge of the tooth; a count of accessory cusps for the lingual cingulum is difficult to establish but at least ten cusps are visible. A marked constriction (or neck) at the crown-root junction is observed all round the tooth.

The sixth maxillary tooth is best preserved on the right side (Fig. 5A, B). The crown is slightly longer but slightly wider than the fifth maxillary tooth with a mesiodistal length of 4.4 $\mathrm{mm}$, a labiolingual width of $3.5 \mathrm{~mm}$ a height of $2.7 \mathrm{~mm}$. The height of the sixth tooth including the crown and root is $7.6 \mathrm{~mm}$. In occlusal view, the mesiodistal carina is not located in the middle of the crown but is close to the labial margin of the crown. A cingulum is present on the entire labial margin and possesses at least 10 accessory cusps on its edge. On the lingual margin, the cingulum is worn out as a wide and concave surface. Remnants of accessory cusps are visible on the distal margin of the tooth. In labial view, the mesiodistal carina consists of three aligned main cusps, the largest and tallest being the central one. The mesial and distal smaller cusps are individualized and worn out. As in other teeth, the crownroot junction is constricted.

The seventh maxillary tooth is only preserved on the left side (Figs. 3, 4). Details of the crown are difficult to assess but the dimensions are nearly the same as the sixth tooth and are as follows: mesiodistal length is $4.3 \mathrm{~mm}$ and labiolingual width is $3.3 \mathrm{~mm}$. The lingual and labial margins of the crown seem to host a cingulum but further details cannot be assessed except that as in the sixth maxillary tooth, the lingual margin is heavily worn out and has the morphology of a wide and concave surface. 
Dentary teeth-Morphologies were observed on slices obtained from CT scans as well as from surface rendering of the mandible (Figs. 6-8). All dentary teeth show the constriction at the crown-root junction as described above for the maxillary dentition. Roots are distinctly long in comparison to the crown and this is irrespective of the crown morphology (about twice as long, Fig. 3A). Roots also become wide when the crown becomes molariform. The first dentary tooth is not preserved but judging from the position and morphology of the left tooth row, the first tooth was projecting anteriorly. The second dentary tooth is visible on both sides of the lower jaw but its surface is damaged (Fig. 6). The crown is low and subconical with a convex mesial edge. The distal edge is steeper than the mesial edge and there is no evidence for a cingulum. The third dentary tooth is mesiodistally longer than the second tooth and its mesial edge presents a small cusp in the continuity of the median carina (Fig. 6B, C). Lingually, the crown surface between these two cusps is depressed. The fourth dentary tooth is mesiodistally longer and its main carina appears to host two cusps as in the third tooth (Fig. $6 \mathrm{~B}, \mathrm{C})$. Further details are not preserved. The fifth dentary tooth is twice as long as the previous tooth and shows the development of a third cuspid on the mesiodistal carina. Although these cuspids are not individualized, the median carina shows a mesial small cusp, a main large cusp and a distal cusp (Fig. 6B, C). The lingual margin of the crown has a cingulum on the distal margin of the crown and possibly also on the mesial margin (Figs. $3 \mathrm{H}$, 6C). Accessory cuspids seem present on its edge but further details cannot be assessed. The sixth dentary tooth is longer than wide and shows the tricuspid arrangement of the median carina. The lingual cingulum is present and possesses several accessory cusps as seen on the right tooth (Fig. 6C). A labial cingulum is present as seen from the CT scan (Fig. 8B). The seventh and eighth right dentary teeth were scanned separately at a high resolution and offer fine details of their morphologies (Fig. 7). The seventh dentary tooth is nearly complete and presents limited abrasion of the crown in comparison to the worn out eighth tooth. In occlusal 
view, the seventh tooth is longer than wide and shows three nearly individualized cusps on its mesiodistal carina. The mesial and distal cusps are smaller than the main central cusp and are not abraded. The central cusp is broken off at its tip. In labial view, the mesial cusp appears taller than the distal cusp. The mesiodistal carina runs right in the middle of the tooth. This carina is sharp as seen from the mesial and distal views and bears shallow apicobasal ridges on its labial surface. The seventh dentary tooth possesses a cingulum on both lingual and labial sides (Fig. 7). Accessory cusps are sharp and well individualized on the mesial half of the lingual cingulum, but seem to merge as an irregular laminar edge on the distal half of the same cingulum. Here, at least 10 accessory cusps are visible. On the labial cingulum, accessory cusps are present but seem to be slightly abraded. The lingual cingulum seems wider than the labial one and with sharper ridges. The eighth dentary tooth offers less details of the crown. In occlusal view, the tooth is longer than wide and consists of a vast concave abraded surface missing most of the median carina. Remnants of the mesiodistal carina show that it was running close to the labial border of the tooth. A cingulum is present on both sides but is heavily worn out on the distal margin of the labial side, including the median carina and the labial cingulum (Figs. 7A, B, 9A). In lingual view, the base of the crown, just below the level of the cingulum shows a series of nine short and widely spaced ridges. These are absent from the labial surface of the crown. In posterior view, two of these ridges are also visible. In labial view, the surface of the root is irregular and ornamented with sinuous shallow depressions. The ninth dentary tooth is the last tooth of the row and is preserved only on the left side. It is smaller than the seventh and eighth teeth and possesses a lingual and labial cingulum (Fig. 8E). However, further details cannot be given because its crown surface is heavily abraded.

\section{Replacement teeth}


There are at least eight instances of replacing teeth observed on the cross section of the CT scan at the available resolution. Replacing teeth are visible on the maxilla or dentary, their degree of development being irrespective of any pattern (anteroposterior or right versus left) and are located at the following tooth positions: second left maxillary tooth, third and sixth right maxillary teeth; second, fourth, sixth and eighth left dentary tooth; fifth right dentary tooth. Replacing teeth consist only of crowns with accessory cusps (e.g. Fig. 8A, D). These crowns have the same shape as the erupted teeth (anteriorly placed teeth are tall whereas posterior teeth are low-crowned) but are sharper and sometime taller due to the fact that they have not worn out yet.

\section{Wear}

The level of wear can be appreciated on the posteriormost left maxillary tooth (seventh) as well as on the eighth and ninth dentary teeth (Figs 7 and 9). All these teeth are nearly worn out flat whereas the seventh dentary tooth is almost intact and exhibits the sharp median carina. In addition, the high-resolution scan through the seventh and eighth right dentary crowns reveals the enamel-dentine junction. At the apex of the seventh dentary crown, the enamel has completely worn out, revealing the dentine (Figs. 7E).

The seventh and eighth dentary teeth have been isolated from the row and their occlusal surface has been examined with a SEM. In the eighth tooth, the median carina is severely eroded (Fig. 9A). Scratch marks are observed on the wide abraded surface of the crown as well as on the edges and are visible at magnification 45 to 70 (when strong), and sufficiently at magnification 300 to 450 in all cases. The seventh dentary tooth bears less marks than the eighth tooth (Fig. 9B, C). On one of the most worn teeth, (the right eighth 
dentary tooth), scratch marks reveal the mode of occlusion. Dimensions of scratch marks vary from $0.33 \mathrm{~mm}$ to $0.03 \mathrm{~mm}$ long by 0.046 to $0.0011 \mathrm{~mm}$ wide (long and thin or short and wide, or the contrary). Their density and strength (width and height) are variable and occur on various locations of the crown: edges of the cingula; labial or lingual median carina faces; mesially to distally along the crown. Over both cingula, few scratch marks are visible, spaced out and perpendicular to the mesiodistal direction with some oblique components (Fig. 9B). At the lingual base of the median carina, scratch marks are numerous and organised in more or less spaced fascicles of two to six parallel stripes (Fig. 9C). These fascicles vary in length and in some cases they overlap. To a few oblique exceptions, their principal direction is perpendicular to the great axis of the median carina. These scratch marks are more numerous, coarser and stronger on the labial side of the median carina near the distal margin (Figs. 9, 10). Their orientation and parameters indicate: 1) the origin of the scratch marks result from the friction of the teeth with food items in the majority of cases, added to the friction between opposing teeth (at least contact of the maxillary top carina and labial mandibulary cingulum); 2) an absence of main mesiodistal jaw movement; and 3) the absence of wear facet with clearly delimited boundaries. Regarding this last point, the labiodistal margin of the eighth dentary crown consists of a lumpy surface (Fig. 9) that accommodates the lingual tip of the opposing sixth maxillary carina, simultaneously on both sides (Fig. 10). Moreover, the median carina of the eighth mandibular tooth interlocks with the lingual side of the opposing median carina (sixth maxillary tooth) as revealed by its worn out surface and by the presence of a groove (Fig. 10A, B). Although this cannot be defined as a polished facet (e.g. Fig. 23 in Ösi, 2013), this spatial arrangement of the interlocking teeth prevents a lateromedial movement of the jaw when it is closed (Fig. 10).

\section{Occlusion}


The areas of maximal tooth-to-tooth contact and friction are constrained by the pattern of occlusion: the dentary tooth row occludes lingually to the maxillary tooth row, therefore the opposing median carinae slide along each other with their apex contacting the base of the cingulum. The skull experienced some post-mortem deformation (as seen from the various crushed and displaced bones on its dorsal surface). In lateral view, the posteriormost region of the right tooth row (Fig. 2B) shows a limited shift between the maxillary and mandibular teeth: the anterior part of the mandibular crown meets the posterior part of the maxillary crown. In addition, the thecodont dentition was maintained in the sockets by conjunctive tissues and its subsequent decay led to some displacement of the teeth. As a consequence, the tooth rows have been slightly displaced and the precise pattern of occlusion cannot be observed. Nevertheless, the left tooth row is nearly complete and offers a better approximation of the tooth-tooth relations than the right tooth row.

More detailed information about occlusion is revealed by the CT scan of the left side of the skull (Fig. 8). The maxillary dentition occludes laterally to the mandibular dentition in the anterior half of the tooth row (Fig. 8A, B, C). Teeth possessing the sharpest median carinae (maxillary teeth 3, 4 and mandibular teeth 6, 7, Fig. 8B, C) show that the median carinae do not contact each other. Instead, the sharp edge of the lingual cingulum of the maxillary crown enters in contact with the labial cingulum of the mandibular crown (Fig. 8B, C), possibly as a result of postmortem displacement of the maxilla and dentary. Taking into account the dorsoventral compression, it is conceivable that the lingual surface of the maxillary median carina was contacting the labial surface of the dentary median carina. As seen from the CT scans, the median carina of the maxillary crown enters in contact with the flat horizontal surface of the dentary bone while the median carina of the dentary crown comes in close contact with the maxillary palate (Fig. 8A, B, C). Finally, the labial cingulum 
of these maxillary crowns and the lingual cingulum of the dentary crowns neither contact bone or tooth. Those cingula are separated from the flat surface of the dentary and from the maxillary palate, respectively, by a gap of about $2 \mathrm{~mm}$ (Fig. 8A, B, C).

In the posteriormost part of the row, the occlusion is not fully lateral. Here, due to the low-crown morphology, part of the occluding surfaces involve the entire occlusal surface of the maxillary crown over the labial half of the occlusal surface of the mandibular tooth (Fig. $8 \mathrm{D}, \mathrm{E})$. Contrary to anteriormost teeth, the lingual cingulum of the maxillary crown is not in contact with the labial cingulum of the mandibular crown. Instead, the lingual cingulum of the maxillary crown contacts the apex of the median carina of the mandibular crown. The labial cingulum of the mandibular crown comes in close contact with the median carina of the maxillary crown on the lingual concave surface of the crown (Fig. 8D, E). In other words, the lingual surface of the main maxillary cusp consists of a wide concave surface that receives both the labial cingulum and the low-crown median carina of the mandibular tooth. As in anterior teeth, the labial cingulum of the maxillary crown and the lingual cingulum of the mandibular crown do not contact any tooth or bone. It is likely that the posteriormost dentition was less affected by postmortem displacement than the anteriormost high-crown dentition. This is because the median carinae (Fig. $8^{*}$ ) and labial cingula of the dentary teeth 8 and 9 have a smooth apex pressed against the wide and concave lingual slope of the corresponding maxillary teeth (Fig. 8D, E). On the other hand, the apices of the median carinae of the corresponding maxillary teeth 5 and 6 are acute (Fig. 8D, E).

Judging from observations of wear pattern as well as occlusion as revealed by the CT scans, we conclude that the jaw movement is fully orthal. No other movement could be inferred, either lateromedial or mesiodistal. Furthermore, the relative positions of the right and left tooth rows (both with maxillary teeth placed labially to dentary teeth) negate the possibility of a lateromedial movement of the jaw. 


\section{PHYLOGENETIC ANALYSIS}

Lavocatchampsa sigogneaurusselli gen. et sp. nov. was coded and included in the data matrix of Pol et al. (2014), which comprises 43 notosuchian genera. The data matrix in total includes 412 characters and 110 taxa (supplementary data). The new taxon is extremely fragmentary and about $10 \%$ of all characters only could be coded. Replicates of 1000 random addition sequences (Wagner trees) were performed under TNT (Goloboff et al., 2003) followed by a first round of TBR branch-swapping. The most parsimonious trees obtained in this search and stored in the RAM were subjected to another round of TBR branch-swapping. Character codings for L. sigogneaurusselli are available in the appendix. We added one state to character 188 to refine the morphological variability of tooth crowns for notosuchians. Notosuchians were updated following the modified definition presented here: Character 188 (modified from Gomani, 1997: char. 46, Buckley et al., 2000: char. 113 and Pol et al., 2014: char. 188): Cusps of posterior teeth: unique apical cusp (0), multicusped, with or without a cingulum (1); median carina(e) flanked by lingual/labial cingulum with cuspidate edges (2).

\section{Results}

The phylogenetic analysis retained over 300,000 most parsimonious trees (best tree length $=$ 1622; $\mathrm{CI}=0.306 ; \mathrm{RI}=0.743)$. The general topology is identical to that obtained by Pol et al. (2014) and Lavocatchampsa sigogneaurusselli gen. et sp. nov. is recovered as a basal ziphosuchian, part of a clade that includes Candidodon itapecuruense, Pakasuchus kapilimai and Malawisuchus mwakasyungutiensis, here recognized as the Candidodontidae. Although clade support is not particularly robust throughout Notosuchia (Bremer decay value of 1 throughout (Fig. 11), the strict consensus is resolved at the level of Candidodontidae and its 
internal relationships. The current phylogenetic analysis recovers Lavocatchampsa, Candidodon, Pakasuchus and Malawisuchus within a single clade in spite of non-preserved characters in Lavocatchampsa, and with a derivation in mosaic of some character states (states more advanced, like in Pakasuchus for 108 and less derived for 188). The Candidodontidae are supported by three optimized synapomorphies. These taxa possess a small number of maxillary teeth i.e. seven to the exception of Pakasuchus, which has even less maxillary teeth (5) (character 108.1); their posterior tooth crowns possess a median carina flanked by cingula with cuspidate edges (character 188.2), although this morphology is slightly different in Pakasuchus as the cuspidate edges are not identified; all these taxa possess cingula at the base of the tooth crown (character 390.1). Within Candidodontidae, the most derived members are Candidodon, Pakasuchus and Malawisuchus, which are united by the presence of an enlarged conical maxillary tooth (character 79.1), absent in Lavocatchampsa. Furthermore, the clade uniting Pakasuchus and Malawisuchus is united by a jugal that does not exceed the anterior margin of the orbit (character 122.0); the posteroventral corner of quadratojugal that does not reach the quadrate condyles (character 141.1 and condition unknown in Lavocatchampsa); the absence of peg on the posterior edge of the mandibular symphysis (character 186.0); the main axis of the ectopterygoid, which is oriented anteriorly and subparallel to the skull longitudinal axis (character 195.1).

\section{DISCUSSION}

\section{Comparison and affinities}

Although it is largely incomplete, Lavocatchampsa sigogneaurusselli gen. et sp. nov. is distinct from any other previously described crocodylomorphs from the Cretaceous of Africa 
and the phylogenetic results recover it as part of a clade of basal ziphosuchians from Africa and South America, here recognized as the Candidodontidae (see Carvalho et al. 2004 and Montefeltro et al. 2009 for previous definitions), which includes the following taxa: Candidodon itapecuruense, Malawisuchus mwakasyungutiensis and Pakasuchus kapilimai. According to our results, the genera Mariliasuchus and Araripesuchus are not members of the Candidodontidae (Carvalho et al. 2004, Montefeltro et al. 2009). The highly derived of $L$. sigogneaurusselli dentition alone is sufficient to discard a referral to crocodylomorph taxa exhibiting conical and more or less compressed tooth crowns (e.g. Araripesuchus or Anatosuchus, e.g. Sereno and Larsson, 2009) or taxa exhibiting ziphodont teeth. $L$. sigogneaurusselli differs from other notosuchians with a complex dental morphology such as Chimaerasuchus paradoxus by the absence of multiple rows of tubercles (Wu et al., 1995; 1996), is dissimilar to sphagesaurids and Notosuchus terrestris with their tear-drop shaped cross section in molariform teeth (Lecuona and Pol, 2008; Pol et al., 2014) and is also dissimilar to Simosuchus clarki with its leaf-shaped teeth (Buckley et al., 2000). As for notosuchians reported from coeval strata in North Africa, Libycosuchus brevirostris is represented by a complete skull but is not comparable to L. sigogneaurusselli. Although its dentition is badly preserved, it is suggested that its dentition is not complex (Buffetaut, 1976; Ösi, 2013). Out of the isolated teeth reported by Larsson and Sidor (1999) from the Kem Kem Beds of Morocco, two morphotypes show a complex crown. However, their morphologies differ from L. sigogneaurusselli by the absence of clear cingula and by the presence of parallel carinae hosting developed rows of tubercles. Although arranged in another fashion, such rows of tubercles have also been described in the dentition of Adamantinasuchus and Yacarerani (Nobre and Carvalho, 2006; Novas et al., 2009). Small African taxa are comparable to L. sigogneaurusselli and exclusively relate to ziphosuchians (sensu Ortega et al., 2000). The closest comparable tooth morphologies are those of two African taxa: 
Malawisuchus mwakasyungutiensis Gomani, 1997, Pakasuchus kapilimai O’Connor et al. 2010 and one Brazilian taxon: Candidodon itapecuruense Carvalho and Campos, 1988. Although L. sigogneaurusselli shares with these three taxa an extremely derived heterodont and molariform dentition, L. sigogneaurusselli can be further distinguished by the absence of caniniform maxillary tooth (79-0). Moreover, the posterior molariform teeth of $L$. sigogneaurusselli do not compare with the posterior molariform maxillary and dentary teeth of P. kapilimai, which show an oblique complementary trough on their occlusal surface (O'Connor et al., 2010). The most comparable teeth in P. kapilimai are the premolariforms, which are subconical and possess a blade-like apical crown. In addition, the morphology is possibly similar in the premolariform maxillary and dentary teeth of L. sigogneaurusselli, which in some instances do possess a hint of a cingulum (Fig. 3) although this was not described in P. kapilimai (but see Fig. 2a in O'Connor et al., 2010). The molariform teeth of L. sigogneaurusselli have a crown flanked by a labial and lingual cingulum with numerous accessory cusps, as is the case in M. mwakasyungutiensis and C. itapecuruense. The main mesiodistal i.e. median carina runs for the entire length of the crown in L. sigogneaurusselli and has the shape of a blade with three cusps, the tallest being the central cusp. In contrast, the mesiodistal carina in M. mwakasyungutiensis and C. itapecuruense has the shape of a tall triangle. Moreover, in C. itapecuruense, this median carina has serrations (Ösi, 2013), which is not the case in L. sigogneaurusselli and M. mwakasyungutiensis. Finally, the accessory cusps present on the edge of the cingulum are smaller but more numerous in $L$. sigogneaurusselli than in M. mwakasyungutiensis or C. itapecuruense (see Gomani, 1997; Carvalho Santos et al., 2011; Ösi, 2013 for comparison).

A number of skull and mandibular features may help further elucidate the affinities of L. sigogneaurusselli gen. et sp. nov. L. sigogneaurusselli possesses seven maxillary alveoli as in M. mwakasyungutiensis or C. itapecuruense but unlike P. kapilimai, which has five 
maxillary alveoli. The dentary alveolar count is nine for L. sigogneaurusselli whereas it is slightly smaller in P. kapilimai with eight alveoli. This cannot be fully compared with $M$. mwakasyungutiensis, which possesses at least five dentary alveoli, and in C. itapecuruense in which the mandible is known from limited material. The posterior tip of the nasals is divided by the anterior frontal process in L. sigogneaurusselli (Figs. 2A, 3E, 165-1). This is not the case in M. mwakasyungutiensis and P. kapilimai where the posterior tip of the nasals meets the frontal along a transverse suture (Gomani, 1997; O'Connor et al., 2010). This suture has not been described in C. itapecuruense. An antorbital fenestra or fossa is present in $L$. sigogneaurusselli as evidenced from the morphology of the left lacrimal (Figs. 2A, 3B). Such a fenestra is present in M. mwakasyungutiensis (Gomani, 1997) and C. itapecuruense (Nobre and Carvalho, 2002) but not in Pakasuchus kapilimai (O'Connor et al., 2010). The mandibular symphysis of L. sigogneaurusselli is long, involves the splenial and terminates posteriorly at the level of the seventh alveolus. This feature is unknown in C. itapecuruense but M. mwakasyungutiensis and P. kapilimai have a splenial involved in the mandibular symphysis. Nevertheless, it is not possible to assess the number of alveoli involved in the symphysis of M. mwakasyungutiensis because of the occluding mandible and this was not described in P. kapilimai.

To summarize, although Lavocatchampsa sigogneaurusselli gen. et sp. nov. is far from complete, this new taxon shares more chararacters with Malawisuchus mwakasyungutiensis and Candidodon itapecuruense than with Pakasuchus kapilimai, notably the maxillary tooth count, the presence of an antorbital fossa or fenestra, and the morphology of the posterior molariform teeth. Lavocatchampsa sigogneaurusselli and Candidodon itapecuruense share similarities in their cingula, although in the latter taxon, the median carina is serrated. 


\section{Paleobiogeography}

Lavocatchampsa sigogneaurusselli gen. et sp. nov. is part of a small clade, the

Candidodontidae, which contains two other African taxa (Pakasuchus and Malawisuchus) as well as a taxon from South America, Candidodon. Their stratigraphic range is the most ancient of all ziphosuchians and spans the Aptian, Albian and Cenomanian, which is consistent with their basal position in this clade. The inclusion of Lavocatchampsa sigogneaurusselli gen. et sp. nov. in the phylogenetic framework of Pol et al. (2014) confirms an initial pre-Aptian radiation of notosuchians of wide distribution, probably initiated when gondwanan landmasses were united (Africa, South America), and also in China, followed by the Turonian-Santonian radiation of advanced notosuchians, which exclusively took place in South America.

South America and Africa formed a single landmass until the end of the early Cretaceous when the first marine sediments are deposited (see Pletsch et al., 2001 for a detailed analysis). This is independently supported by early Cretaceous terrestrial faunal assemblages from South America and Africa (de Broin, 1988; Gheerbrant and Rage, 2006; de Lapparent de Broin, 2000b) and notably among crocodylomorph faunas from the distribution of the freshwater pholidosaurid Sarcosuchus (Buffetaut and Taquet, 1977) and from the small terrestrial crocodylomorph Araripesuchus (Buffetaut and Taquet, 1979), each known from Barremian, Aptian or Albian deposits of Niger and Brazil (see also Sereno and Larsson, 2009). Here, the Candidodontidae, which includes Albian, Aptian and Cenomanian members from Brazil and continental Africa also lends support to the hypothesis of a vicariant faunal assemblage initially present on a landmass known as West Gondwana (i.e South America and Africa, see Gheerbrant and Rage, 2006 for a review). 
To the exception of isolated teeth from the upper Cretaceous of Brazil (Montefeltro et al., 2009), Candidodontidae have not been reported in post-Cenomanian deposits of South America. Their absence could be a consequence of faunal replacement with advanced notosuchians, when they diversified during the Coniacian-Santonian (Pol et al., 2014) or of a poorly sampled fossil record. As concerns Africa, it has recently been suspected that the dinosaur beds of Malawi, and the Galula Formation of Tanzania could be Late Cretaceous in age rather than Early Cretaceous (Le Loeuff et al., 2012). Therefore, both Malawisuchus mwakasyungutiensis and Pakasuchus kapilimai could represent the youngest members of Candidodontidae. But until this becomes proven, knowledge on the Late Cretaceous evolutionary history of crocodylomorphs remains extremely scarce with a single fragmentary taxon, Trematochampsa taqueti known from the Turonian-Santonian of In Beceten, Niger (Buffetaut, 1976). Recent studies proposed a peirosaurid affinity for Trematochampsa taqueti (Sertich and O'Connor, 2014) and members of this group are also recovered from AlbianCenomanian deposits of Africa such as the Kem-Kem Beds of Morocco with the genus Hamadasuchus (Buffetaut, 1994; Larsson and Sues, 2007) and from the Galula Formation of Tanzania with the genus Rukwasuchus (Sertich and O'Connor, 2014). Peirosauridae are otherwise very diverse in Late Cretaceous deposits of South America, which would constitute again another faunal similarity with continental Africa. Whether Candidodontidae managed to survive in post-Cenomanian times in continental Africa still needs to be assessed but is challenging due to a paucity of fossiliferous continental outcrops.

The absence of Candidodontidae in the Maastrichtian of India and Madagascar could be explained by the early separation of India and Madagascar from continental Africa in the late Jurassic followed by a complete separation from other Gondwanan landmasses in the early Cretaceous (see Turner and Sertich, 2010 for a review of notosuchian dispersal in Gondwana), therefore earlier than the radiation of Candidodontidae in continental Africa. 
However, Madagascar has no reported fossiliferous localities contemporaneous with the KemKem Beds making faunal comparison and paleobiogeographic hypotheses with Aptian, Albian or Early Cenomanian continental faunas of mainland Africa somehow weak.

\section{Food processing and ecology}

The extremely high dental diversity seen in Notosuchia has led to interpret the diet of these small terrestrial crocodylomorphs as very diverse. This has been recently discussed at length by Ösi (2013) who summarizes the presumed diets of Malawisuchus mwakasyungutiensis as insectivorous; Candidodon itapecuruense as having an herbivorous diet based on morphological similarities with ankylosaurians - although Ösi (2013) also discusses the presence of caniniform teeth and concludes to a more diverse diet for this taxon - and Pakasuchus kapilimai as a carnivorous form.

In Malawisuchus mwakasyungutiensis and Pakasuchus kapilimai, the articular capsule has a distinctly elongate morphology and it was hypothesized the capability of fore and aft movement of the lower jaw, unlike in modern forms (Clark et al., 1989; O'Connor et al., 2010; and review in Ösi, 2013). The articular is not preserved in Candidodon itapecuruense and Lavocatchampsa sigogneaurusselli gen. et sp. nov. but evidence for jaw movement can be gleaned from tooth wear, by studying the preferential orientation of scratch marks over the occlusion surface of teeth. In Lavocatchampsa sigogneaurusselli gen. et sp. nov., the absence of mesowear or wear facets is noticeable on the teeth to the exception of the sixth maxillary and eighth mandibular crowns, which are the most abraded teeth of the jaws. According to SEM, microwear is mostly vertical (Fig. 9), thus the main component of jaw closure in Lavocatchampsa sigogneaurusselli gen. et sp. nov. is orthal (Fig. 10). Ösi (2013) also 
recognized a mainly orthal movement of the jaw in Candidodon itapecuruense based on tooth wear orientation and muscle configuration.

In Lavocatchampsa sigogneaurusselli gen. et sp. nov., some cheek teeth are extremely abraded (Figs. 9A, 10), suggesting either an abrasive diet or a delayed replacement of the dentition. Indeed, the dentary bone and the arrangement of teeth on it are strongly concave in lateral view, with a maximum concavity at the level of the last maxillary teeth. This corresponds to the zone of maximum compression. Here, molariform teeth have a mesiodistally elongate root and low crowns, perfectly suited to accommodate dorsoventral stress. This suggests that Lavocatchampsa sigogneaurusselli gen. et sp. nov., despite its small size, crushed on tough materials, which would likely be abrasive.

Timing of tooth replacement is revealed by the CT scans. All replacing teeth consist of crowns. In this specimen, not a single replacement tooth has developed the root yet, indicating that replacement was not imminent. Roots develop last when the enamel stops forming (Jernvall and Thesleff, 2012). Computed tomography reveals that the replacing dentition is randomly distributed in the jaw and is independent of the degree of crown wear, thus replacement of the dentition was continuous but slow. In early mammals, there is a gradual reduction in tooth replacement and this was attributed to the evolution of precise occlusion (Kielan-Jaworowska et al., 2004). In the newly described Lavocatchampsa sigogneaurusselli gen. et sp. nov., the complex crown morphology, the random and delayed timing of eruption and the mainly orthal jaw closure account for the extremely worn out dentition. The mesiodistal median carina would permit to cut through food material while the labial and lingual cingula might help retaining food items thanks to the small puncturing cuspids placed along the edges of the cingula. Although this cannot be verified, it seems plausible that Lavocatchampsa sigogneaurusselli gen. et sp. nov. was feeding on a variety of hard-shelled invertebrates such as insects of small size. The radiation of notosuchians is explosive and 
begins in the Aptian. At the same time, the diversification of angiosperms and beetles was thought to be concomitant with that of mammals (Ahrens et al., 2014). Given the morphological convergence between some mammals and Candidodontidae, a similar ecological and evolutionary link could be worth testing in Gondwanan faunal assemblages.

\section{ACKNOWLEDGMENTS}

B. Fectay and C. Bidaut (“La Mémoire de la Terre”, Aumont), and D. E. Russell and D. Sigogneau-Russell (MNHN, Paris) (discovery and purchase); J. F. Bonaparte (Buenos Aires), Z. Gasparini and M. de la Fuente (La Plata), P. M. Brito (Rio de Janeiro) (documentation and comparative collections); F. Renoult, B. Battail, R. Allain (comparative collections, MNHN Paris); C. Weber Chancogne (SEM, MNHN Paris); D. Serrette (MNHN Paris, initial photographs); F. Pilard (MNHN Paris, initial drawing), P. Vincent (MNHN, Paris), R. Amiot and E. Mattioli (LGLTPE, Lyon). C. Charles (IGFL, ENS Lyon) provided much helpful technical assistance with the CT scans. CT scans were financially supported by the Laboratoire de Géologie de Lyon: Terre, Planète, Environnement (LGLTPE, UMR CNRS 5276). Finally, we thank the two reviewers A. Ösi and D. Pol as well as the editor A. Turner for their comments that helped improve the quality of this manuscript.

\section{LITERATURE CITED}

Ahrens, D., J. Schwarzer, and A. P. Vogler. 2014. The evolution of scarab beetles tracks the sequential rise of angiosperms and mammals. Proceedings of the Royal Society, B. 281: doi: 10.1098/rspb.2014.1470.

Bassoullet, J. P., and J. Iliou. 1967. Découverte de Dinosaures associés à des Crocodiliens et des Poissons dans le Crétacé inférieur de l'Atlas saharien (Algérie). Comptes rendus sommaires de la Société géologique de France 7: 294-295. 
Bellion, Y., J. P. Lefranc, and J.-G. Michard. 1992. Précisions sur l'âge des sédiments mésocénozoïques à l'ouest de l'Adrar des Iforas (Sahara, Mali, Afrique de l'ouest). Implications paléogéographiques. Actes du $115^{\mathrm{e}}$ Congrès National des Sociétés savantes (Avignon, 1990), Section Sciences, Géologie Africaine, Actes du $3^{\mathrm{e}}$ colloque, Paris, CTHS, 7-27.

Bouaziz, S., E. Buffetaut, M. Ghanmi, J. J. Jaeger, M. Martin, J. M. Mazin, and H. Tong. 1988. Nouvelles découvertes de vertebrés fossiles dans l'Albien du Sud tunisien, Bulletin de la Société géologique de France 4: 335-339.

Buckley, G. A., C. A. Brochu, D. W. Krause, and D. Pol. 2000. A pug-nosed crocodyliform from the Late Cretaceous of Madagascar. Nature 405: 941-944.

Buffetaut, E. 1976. Der Land-Krokodilier Libycosuchus Stromer und die Familie Libycosuchidae (Crocodylia, Mesosuchia) aus der Kreide Afrikas. Bayerische Staatssammlung für Palaeontologie und Historische Geologie, Mitteilungen, Munich 13: 17-28.

Buffetaut, E. 1994. A New Crocodilian from the Cretaceous of Southern Morocco. Comptes rendus de l'Académie des Sciences II 319: 1563-1568.

Buffetaut, E. 2001. On the age of the Mid-Cretaceous Vertebrate-Bearing Formation of North Africa. In : Colloque sur le Cénomanien, Oc. 20-21, Bulletin de la Société d'Etude des Sciences Naturelles d'Elbeuf. Rouen, France, 20-22.

Buffetaut, E., R. Bussert, and W. Brinkman. 1990. A new nonmarine vertebrate fauna in the Upper Cretaceous of northern Sudan. Berliner Geowissenschaftlische Abhandlungen A 120: 183-202.

Buffetaut, E., and P. Taquet. 1977. The Giant Crocodilian Sarcosuchus in the Early Cretaceous of Brazil and Niger. Paleontology 20: 203-208. 
Buffetaut, E., and P. Taquet. 1979. Un nouveau Crocodilien mésosuchien dans le Campanien de Madagascar, Trematochampsa oblita, n.sp.. Bulletin de la Société Géologique de France 2: 183-188.

Busson, G., and A. Cornée. 1995. The Sahara from the Middle Jurassic to the Middle Cretaceous: Data on environments and climates based on outcrops in the Algerian Sahara. African Earth Sciences 12: 85-105.

Carvalho, I. S. 1994. Candidodon: um crocodile com heterodontia (Notosuchia, Cretáceo Inferior-Brasil). Anais da Academia Brasileira de Ciências 66: 331-346.

Carvalho, I. S., and D. A. Campos. 1988. Um mamífero triconodonte do Cretáceo Inferior do Maranhão, Brasil. Anais da Academia Brasileira de Ciências 60: 437-446.

Carvalho, I. S., L. C. B. Ribeiro, and L. S. Avilla. 2004. Uberabasuchus terrificus sp. nov., a new Crocodylomorpha from the Bauru Basin (Upper Cretaceous), Brazil. Gondwana Research 7: 975-1002.

Carvalho Santos, R. de, I. de Souza Carvalho, M. A. Araújo Medeiros, and R. A. Barros Santos. 2011. Dentes de Candidodon itapecuruense da lha do Cajual (Formação Alcântara), Cretáceo Do Maranhão. XXII Congresso Brasileiro de Paleontologia. Paleontologia: Caminando pelo tempo 22: 379-383.

Cavin, L., H. Tong, L. Boudad, C. Meister, A. Piuz, J. Tabouelle, M. Aarab, R. Amiot, E. Buffetaut, G. Dyke, S. Hua and J. Le Loeuff. 2010. Vertebrate assemblages from the early Late Cretaceous of southeastern Morocco : an overview. Journal of African Earth Sciences 57: 391-412.

Choubert, G. 1956. Lexique stratigraphique du Maroc. Infracénomanien pp 75-76 in : R. Furon (ed.) Lexique Stratigraphique International, 4 (1a). CNRS, Paris. 
Clariond, L. 1933. Les terrains primaires et la Hammada de Taouz (Confins algéro-marocains du Sud). Compte rendu sommaire des séances de la Société Géologique de France $193347-48$.

Clark, J. M., L. L. Jacobs, and W. R. Downs. 1989. Mammal-Like dentidon in a Mesozoic Crocodylian. Science 244: 1064-1066.

de Broin, F. 1965. Etude paléontologique de quelques crocodiliens du Sahara. Thèse de Doctorat de 3e cycle. Faculté des Sciences de l’Université de Paris, 147 pp.

de Broin, F. 1988. Les Tortues et le Gondwana. Examen des rapports entre le fractionnement du Gondawana et la dispersion géographique des Tortues pleurodires à partir du Crétacé. Studia Geologica Salmanticensis, Studia Palaeocheloniologica 2: 103-142.

de Broin, F., C. Grenot, and R. Vernet. 1971. Sur la découverte d'un nouveau gisement de Vertébrés dans le Continental Intercalaire Saharien: La Gara Samani (Algérie). Comptes rendus de 1'Académie des Sciences, Paris, D 272: 1219-1221.

de Broin F., and P. Taquet. 1966. Découverte d'un crocodilien nouveau dans le Crétacé inférieur du Sahara. Comptes rendus de l'Académie des Sciences, Paris, D 262: 23262329.

de Lapparent, A. F. 1951. Découverte de Dinosauriens associés à une faune de Reptiles et de Poissons dans le Crétacé inférieur de l'Extrême Sud tunisien. Comtes rendus de l'Académie des Sciences 232: 1430-1432.

de Lapparent, A. F. 1960. Les dinosauriens du « continental intercalaire » du Sahara Central. Mémoires de la Société géologique de France NS, 88A, 57 pp. de Lapparent de Broin, F. 2000a. African chelonians from the Jurassic to the Present. A preliminary catalogue of the African fossil chelonians. Palaeontologia Africana 36: $43-82$. 
de Lapparent de Broin, F. 2000b. The oldest pre-Podocnemidid turtle (Chelonii, Pleurodira), from the early Cretaceous, Ceará state, Brasil, and its environment. Treballs Museo de Geologia de Barcelona 9: 43-95.

de Lapparent de Broin, F. 2002. Elosuchus, a new genus of crocodile from the lower Cretaceous from the north of Africa. Comptes Rendus Palevol 1: 275-285.

Dutheil, D. B. 2000. Les Cladistia du Cénomanien continental du Sud-est marocain et les ichthyofaunes associées. Implications biostratigraphiques, taphonomiques, paléoécologiques et paléobiogéographiques. Mémoire pour l'obtention du diplôme de 1’Ecole Pratique des Hautes Etudes. E.P.H.E., Sciences de la Vie et de la Terre, Montpellier : $146 \mathrm{pp}$.

Furon, R. 1955. Continental Intercalaire, pp. 17-19 in : R. Furon, M., Lelubre, T., Monod, J.M. Pires Soares, and F. Tessier, Lexique Stratigraphique International, Afrique, 2, Sahara, Afrique Occidentale Française et Portugaise, CNRS, Paris, 68 pp.

Gasparini, Z. B. 1971. Los Notosuchia del Cretácio de America del sur como un Nuevo infraorden de los Mesosuchia (Crocodilia). Ameghiniana 8: 83-103.

Gheerbrant, E., and J. C. Rage. 2006. Paleobiogeography of Africa: how distinct from Gondwana and Laurasia? Palaeogeography, Palaeoclimatology, Palaeoecology 241: 224-246.

Gmelin, J. F. 1789. Caroli a Linné, Systema Naturae pp. 1033-1516 in G. E. Beer (ed.), Tom. I. Pars III. Leipzig, Germany.

Goloboff, P. A., J. S. Farris, and K. Nixon. 2003. TNT: tree analysis using new technologies (Program and documentation available from the authors and at http:www.zmuc.dk/public/phylogeny).

Gomani, E. M. 1997. A crocodyliform from the Early Cretaceous Dinosaur Beds, Northern Malawi. Journal of Vertebrate Paleontology 17: 280-294. 
Jernvall J., and I. Thesleff. 2012. Tooth shape formation and tooth renewal: evolving with the same signals. Development 139: 3487-3497.

Kilian C. 1931. Des principaux complexes continentaux du Sahara. Comptes Rendus Sommaires des Séances de la Société Géologique de France 9: 109-111.

Kielan-Jaworowska, Z., R. L. Cifelli, and Z. -X. Luo. 2004. Mammals from the Age of Dinosaurs - origins, evolution, and structure. Columbia University Press, New York.

Larsson, H. C. E., and B. Gado. 2000. A new Early Cretaceous crocodyliform from Niger. Neues Jahrbuch für Geologie und Paläontologie Abhandlungen 217: 131-142.

Larsson, H. C. E., and C. A. Sidor. 1999. Unusual crocodyliform teeth from the Late Cretaceous (Cenomanian) of southeastern Morocco. Journal of Vertebrate Paleontology 19: 398-401.

Larsson, H. C. E., and H. D. Sues. 2007. Cranial osteology and phylogenetic relationships of Hamadasuchus rebouli (Crocodyliformes: Mesoeucrocodylia) from the Cretaceous of Morocco. Zoological Journal of the Linnean Society 149: 533-567.

Lavocat, R. 1948. Découverte de Crétacé à Vertébrés dans le soubassement de la Hammada du Guir (Sud marocain). Comptes rendus hebdomadaitres des séances de l'Académie des Sciences 226: 1291-1292.

Lavocat, R. 1954. Reconnaissance géologique dans les Hammadas des confins algéromarocains du sud. Notes et Mémoires du Service géologique du Maroc, 116: 147 pp.

Lavocat, R. 1955. Découverte d'un crocodilien du genre Thoracosaurus dans le Crétacé supérieur d'Afrique. Bulletin du Muséum National d'Histoire Naturelle 27: 338-340.

Lecuona, A., and D. Pol. 2008. Tooth morphology of Notosuchus terrestris (Notosuchia : Mesoeucrocodylia) : new evidence and implications. Comptes Rendus Palevol 7 : $407-417$. 
Le Loeuff, J., E. Läng, L. Cavin, and E. Buffetaut. 2012. Between Tendaguru and Bahariya : on the age of the Early Cretaceous dinosaur sites from the continental intercalaire and other African formations. Journal of Stratigraphy 36: 486-502.

Le Loeuff, J., E. Métais, D. B. Dutheil, J. L. Rubino, E. Buffetaut, F. Lafont, L. Cavin, F. Moreau, H. Tong, C. Blanpied, and A. Sbeta. 2010. An Early Cretaceous vertebrate assemblage from the Cabao Formation of NW Libya. Geological Magazine 147: 750759.

Mahler, L. 2005. Record of Abelisauridae (Dinosauria: Theropoda) from Cenomanian Morocco. Journal of Vertebrate Paleontology 25: 236-239.

Martin, J. E., and M. J. Benton. 2008. Crown Clades in Vertebrate Nomenclature: Correcting the Definition of Crocodylia. Systematic Biology 57: 173-181.

Mateer, N. J., P. Wycisk, L. L. Jacobs, M. Brunet, P. Luger, M. A. Arush, F. Hendriks, T. Weissbrod, G. Gvirtzman, E. Mbede, A. Dina, R. T. J. Moody, G. Weigelt, H. A. ElNakhal, J. Hell, and J. Stets. 1992. Correlation of nonmarine Cretaceous strata of Africa and the Middle East. Cretaceous Research 13: 273-318.

Montefeltro, F. C., C. R. Laurini, and M. C. Langer. 2009. Multicusped crocodyliform teeth from the Upper Cretaceous (São José do Rio Preto Formation, Bauru Group) of São Paulo, Brazil. Cretaceous Research 30: 1279-1286.

Nobre, P. H., and I. S. Carvalho. 2002. Osteologia do crânio de Candidodon itapecuruense (Crocodylomorpha, Mesoeucrocodylia) do Cretáceo do Brasil. In: Simpósio Sobre o Cretáceo Do Brasil 6, Simposio Sobre El Cretacico De América Del Sur, 2, 2002. Boletim 77-82.

Nobre, P. H., and I. S. Carvalho. 2006. Adamantinasuchus navae: a new gondwanan Crocodylomorpha (Mesoeucrocodylia) from the Late Cretaceous of Brazil. Gondwana Research 10: 370-378. 
Novas, F. E., D. F. Pais, D. Pol, I. S. Carvalho, A. Scanferla, A. Mones, and M. S. Riglos. 2009. Bizarre notosuchian crocodyliform with associated eggs from the upper Cretaceous of Bolivia. Journal of Vertebrate Paleontology 29: 1316-1320.

O’Connor, P. M., J. J. W. Sertich, N. J. Stevens, E. M. Roberts, M. D. Gottfried, T. L. Hieronymus, Z. A. Jinnah, R. Ridgely, S. E. Ngasala, and J. Temba. 2010. The evolution of mammal-like crocodyliforms in the Cretaceous period of Gondwana. Nature 466: 748-751.

Ortega, F., Z. Gasparini, A. D. Buscalioni, and J. O. Calvo. 2000. A new species of Araripesuchus (Crocodylomorpha, Mesoeucrocodylia) from the lower Cretaceous of Patagonia (Argentina). Journal of Vertebrate Paleontology 20: 57-76.

Ösi, A. 2013 The evolution of jaw mechanism and dental function in heterodont crocodyliforms. Historical Biology 26: 1-137.

Pletsch, T., J. Erbacher, A. E. L. Holbourn, W. Kuhnt, M. Moullade, F. E. Oboh-Ikuenobede, E. Söding, and T. Wagner. 2001. Cretaceous separation of Africa and South America: the view from the West African margin (ODP Leg 159). Journal of South American Earth Sciences 14: 147-174.

Pol D, P. M. Nascimento, A. B, Carvalho, C. Riccomini, R. A, Pires-Domingues, and H. Zaher. 2014. A New Notosuchian from the Late Cretaceous of Brazil and the Phylogeny of Advanced Notosuchians. PLoS ONE 9(4): e93105. doi:10.1371.

Prasad G. V. R., and F. de Lapparent de Broin. 2002. Cretaceous crocodile remains from Naskal (India): comparisons and biogeographic affinities. Annales de Paléontologie 88: 19-71.

Rauhut, O., and A. López-Arbarello. 2005. Wirbeltierreste aus der "mittleren” Kreide des Kem Kem, Marokko. Freunde der Bayerischen Staatssamlung für Paläontologie und Geologie, Jahresbericht und Mittelungen 34: 41-45. 
Schmidt, D., and C. Werner. 1998. Early Cretaceous coastal plain sediments of the Mugher Mudstone Formation, Abay River Basin, Ethiopia. Zentralblatt für Geologie, Paläontologie 1: 293-309

Sereno, P. C., D. B., Dutheil, M., Iarochene, H. C. E. Larsson, G. H. Lyon, P. M. Magwene, C. A. Sidor, D. J. Varricchio, and J. A. Wilson. 1996. Predatory dinosaurs from the Sahara and Late Cretaceous faunal differentiation. Science 272: 986-991.

Sereno, P. C., and H. C. E. Larsson. 2009. Cretaceous crocodyliforms from the Sahara. ZooKeys 28: 1-143.

Sertich, J. J. W., and P. M. O’Connor. 2014. A new crocodyliform from the middle Cretaceous Galula Formation, southwestern Tanzania. Journal of Vertebrate Paleontology 34: 576-596.

Sigogneau-Russell, D. 1995. Two possibly aquatic triconodont mammals from the Early Cretaceous of Morocco. Acta Palaeontologica Polonica 40: 149-162.

Sigogneau-Russsell, D. 2003. Diversity of Triconodont Mammals from the Early Cretaceous of North Africa - Affinities of the Amphilestids. Palaeovertebrata 32: 27-55.

Sigogneau-Russell, D., M. Monbaron, and E. De Kaenel, 1990. Nouvelles données sur le gisement à mammifères mésozoïques du Haut-Atlas marocain. Geobios 23: 461-483. Sigogneau-Russell, D., M. Monbaron, and D. E. Russell, 1988. Découverte de Mammifères dans le Mésozoïque moyen d'Afrique. Comptes Rendus de l'Académie des Sciences, Paris, II 307: 1045-1050.

Stromer, E. 1925. Ergebnisse der Forschungsreisen Prof. E. Stromers in den Wüsten Ägyptens. II. Wirbeltierreste der Baharije-Stufe (unterstes Cenoman). 7. Stomatosuchus inermis Stromer, ein schwach bezahnter Krokodilier und 8. Ein skelettrest des Pristiden Onchopristis numidus Haug sp. Abhandlungen Bayerische Akad. der Wissenschaften Math-Naturwissenschaftliche Abteilung, München 30: 1-9. 
Stromer, E. 1933. Ergebnisse der Forschungsreisen Prof. E. Stromers in den Wüsten Ägyptens. II. Wirbeltierreste der Baharije-Stufe (unterstes Cenoman). 12. Die procölen Crocodilia. Abhandlungen der bayererischen Akademie der Wissenschaften, Mathematisch-naturwissenschaftliche Abteilung. N.F. 15: 55 pp.

Taquet, P. 1976. Géologie et paléontologie du gisement de Gadoufaoua (Aptien du Niger). Cahiers de Paléontologie, CNRS, Paris, 191 pp.

Taquet, P., and D. A. Russell. 1998. New data on spinosaurid dinosaurs from the Early Cretaceous of the Sahara. Comptes Rendus de l'Académie des Sciences, Sciences de la terre et des planètes $327: 347-353$.

Turner, A. H. 2004. Crocodyliform biogeography during the Cretaceous: evidence of Gondwanan vicariance from biogeographical analysis. Proceedings of the Royal Society of London B 271: 2003-2009.

Turner, A. H. and J. W. Sertich 2010. Phylogenetic history of Simosuchus clarki (Crocodyliformes: Notosuchia) from the Late Cretaceous of Madagascar Journal of Vertebrate Paleontology 30: 177-236.

Walker, A. D. 1970. A revision of the Jurassic reptile Hallopus victor (Marsh), with remarks on the classification of crocodiles. Philosophical Transactions of the Royal Society London B 257: 323-372.

Werner, C. 1995. Neue Funde von mesozoischen Wirbeltieren in Äthiopien. Berliner Geowissenschaften Abhandlungen, E 16: 377-383.

Werner, C., and J. -C. Rage. 1994. Mid-Cretaceous snakes from Sudan. A preliminary report on an unexpectedly diverse snake fauna. Comptes Rendus de l'Académie des Sciences, Paris II 319: 241-252. 
Whetstone, K. N., and P. J. Whybrow. 1983. A 'cursorial' crocodilian from the Triassic of Lesotho (Basutoland), southern Africa. Occasional Papers of the Museum of Natural History of the University of Kansas 106: 1-37.

Wu, X. C., and H. D. Sues. 1996. Anatomy and phylogenetic relationships of Chimaerasuchus paradoxus, an unusual crocodyliform reptile from the Lower Cretaceous of Hubei, China. Journal of Vertebrate Paleontology 16: 688-702. Wu, X. -C., H. -D. Sues, and A. Sun. 1995. A plant-eating crocodyliform reptile from the Cretaceous of China. Nature 376: 678-680.

Submitted April 28, 2015; accepted Month DD, YYYY.

\section{Figure captions}

FIGURE 1. Map of Morocco with Guir Hamada and Kem Kem area framed in the upper left corner. The extraction locality of Lavocatchampsa sigoneaurusselli gen. nov. et sp. nov. (MNHN F MRS 2097) is indicated on the map by a diamond and shown in the accompanying picture. [planned for page width]

FIGURE 2. Photographs of Lavocatchampsa sigoneaurusselli gen. nov. et sp. nov. (MNHN F MRS 2097) in A, dorsal; B, ventral and C, right lateral views. [planned for column width]

FIGURE 3. Three-dimensional surface rendering of the skull and mandible of Lavocatchampsa sigoneaurusselli gen. nov. et sp. nov. (MNHN F MRS 2097). Skull in A, right lateral; B, left lateral, C; posterior, D; anterior, E; dorsal, F; palatal; and mandible in $\mathbf{G}$, ventral and $\mathbf{H}$, occlusal views. The right dentary teeth (seventh and eighth) were CT scanned separately and do not appear in the reconstructions. [planned for page width] 
FIGURE 4. Line drawings of the skull and mandible of Lavocatchampsa sigoneaurusselli gen. nov. et sp. nov. (MNHN F MRS 2097). Skull in A, right lateral; B, left lateral, C; posterior, D; anterior, E; dorsal, F; palatal; and mandible in $\mathbf{G}$, ventral and $\mathbf{H}$, occlusal views. Abbreviations: aof, antorbital fossa; cs, choanal septum; den, dentary; ec, ectopterygoid; fr, frontal; j, jugal; l, lacrimal; mx, maxilla; n, nasal; pa, palatine; pfr, prefrontal; san, surangular; sp, splenial; 1-7: maxillary alveolus count; d1-d9: dentary alveolus count. The right dentary teeth (seventh and eighth) were CT scanned separately and do not appear in the drawings. [planned for page width]

FIGURE 5. Three-dimensional surface rendering of the right maxillary dentition of Lavocatchampsa sigoneaurusselli gen. nov. et sp. nov. (MNHN F MRS 2097). Posterior molariform teeth in $\mathbf{A}$, labial and $\mathbf{B}$, occlusal views; teeth from the anterior and mid regions in C, labial and D, lingual views. [planned for page width]

FIGURE 6. Three-dimensional surface rendering of $\mathbf{A}$, the mandible of Lavocatchampsa sigoneaurusselli gen. nov. et sp. nov. (MNHN F MRS 2097) and details of the right tooth row in $\mathbf{B}$, labial and $\mathbf{C}$, lingual views. [planned for page width]

FIGURE 7. Three-dimensional surface rendering of the seventh and eighth right mandibular teeth of Lavocatchampsa sigoneaurusselli gen. nov. et sp. nov. (MNHN F MRS 2097). A, labial; B, occlusal; C, lingual views and D, distal views; $\mathbf{E}$, transverse section through the $7^{\text {th }}$ tooth with a detailed view of the apex showing the abraded enamel-dentine junction. Abbreviations: la.c., labial cingulum; li.c., lingual cingulum. [planned for column width] 
FIGURE 8. Transversal CT sections through the left maxillary and mandibular tooth row of Lavocatchampsa sigogneaurusselli gen. nov. et sp. nov. (MNHN F MRS 2097).

Abbreviations: upper numbers refer to maxillary tooth positions; lower numbers refer to mandibular tooth positions; den, dentary; lab., labial; la.c., labial cingulum; li.c., lingual cingulum; lin, lingual; mx, maxilla; r, replacement tooth; *, median carina. [planned for page width]

FIGURE 9. Scanning Electron Microscope view of the right eighth mandibular tooth of Lavocatchampsa sigogneaurusselli gen. nov. et sp. nov. (MNHN F MRS 2097) showing the pattern of abrasion. A, Occlusal view showing examined areas; $\mathbf{B}$, detail of the posterolingual edge of the cingulum; $\mathbf{C}$, detail of the lingual side of the slope of the median carina. * indicates the median carina; the arrows indicate the extension of the worn lumpy occlusal surface on the labiodistal area of the crown. [planned for column width]

FIGURE 10. Wear pattern observed on the right posterior occluding teeth of Lavocatchampsa sigogneaurusselli gen. nov. et sp. nov. (MNHN F MRS 2097). A, B, stereopairs of the sixth maxillary tooth in occlusal view. Note the groove (arrow) positioned lingually to the median carina; $\mathbf{C}$, simplified sketch showing the relation of the sixth maxillary crown with the eighth mandibular crown during an orthal jaw movement; D, Scanning Electron Microscope view of the right eighth mandibular tooth in labiodistal view. * indicates the median carina; black arrows indicate the incision on the maxillary tooth occlusal surface and the white arrows indicate the extension of the worn lumpy surface on the mandibular tooth. [planned for page width] 
FIGURE 11. Phylogenetic hypothesis from this work placing Lavocatchampsa sigogneaurusselli gen. nov. et sp. nov. (MNHN F MRS 2097) within Candidodontidae, a clade sitting in a basal position within Ziphosuchia. The stratigraphic distribution of taxa are indicated. Figures denote Bremer decay indices. [planned for column width]

\section{Data matrix used to explore the phylogenetic affinities of Lavocatchampsa}

xread

412110

Gracilisuchus

000000??0?000000000000?0?000000000?0??0?0?00000?000???0000?0???0?000?100000?0 0000000?0???0000?0?0000003012?00?0??????01?01000??1?01???000001002?0???0000??? ?000???00000?0000????000???0????0???????0000?00000?0?000000000?0?0000?00?0?0??0 ?0??000??0?00??1?0?0?001???0?110???1??01000??0??????????????0????????????????????? ????????00000????????010?0000???00000???0???????????????????????0??000???000???0? 0??0???????0???

Terrestrisuchus 000??00??0??000000?000?0?00?000?110?00000?00000?000??0?000?000????00???010??0? 000000?010?0000?02000001301??0110??00?00?00100??10?00?110?0?0??[01]110???00000 ???000???00100?000??001?00???0????0??????00????00??0?0??0?0???????????0?????????0 ?????0?????????????0?00????????????????????????????????????0??????0???0???0000?00 ?????0?00??0??????????????????????????????????????????????????????????????????????? ?????????? 
Dibothrosuchus

000?00?030??001???000000??????00110000000?00000?0000?00000?0?0102000?000100?0 010?000?????2000?0?????013010?0110?0?0?000001001?10?00?1?0?0101011100??000001? ?00?0?00?1000000100010000?000??00?0?00100001000100?0?000000000?000000?0?0000? ?0??00000??0000?00?0?0?000?0?0?1101?01??01000??0??00100?00000000????00???00?00 0000?00????00000000??????????????????00?0?00??00?0??0?0?????0?00??0?000??000???0 0????????00?0??????000

Protosuchus_richardsoni

$21000001300000011010000100000100010001010 ? 00201001111110010101103011 ? 100210$ $001010100001100[1234] 00 ? 120011010011102101010100[01] 000000 ? 01 ? ? 01 ? ? 10010[01] 01$ 01000100???0110000000000000001?00100000?0???0000?0100120000011110??001000?01 0?0000?0?0000??0?000000??00000000100000????0??10?????00?000??0000???0?000?000? 0????00?0?00??0000100?????0000101?0000???00010100?0?000?0?0?0000??0?01?[01]0?00 ????????0?0000?00000???000000?00?????0?0

Protosuchus_haughtoni 2100?0?1300000?11010000100?00100010001010?0020100111?1100101?1?03011?10?2?00 0101??????????????12?????10?1110??0??????0[01]??000[01]?01?001??10010?01??1?0100? ??011?000??0?1000000100???0000?00??00?0?010?120?00011?00?100100010?0000?0?0?00 00??0?000000??000000001?0?00????00?10??????01000??10?0??00?00?000?00???000????? ????????????????????????????????????????000?0001??00??0?010[01]??0?000?00000???00? ??00?????00000??0?????0?0 
Hemiprotosuchus

?10?00?1???????10010?0??00?0010?11????01??0020?00?11?1100101??1?3?11??0?21????0 1?????????0????1200?1?1001??0?????????000?000?????00???00000??10?????00???????0?0 ??0??00?0??????1?0000?0????0???0???12???001??10?00?00?01??00???0???0?????0?????00 ???00???00????00????0??10????????0????0??????0?0????0??????????????00?????????????? ?????????????????????????0?????????0??0????????????????????????????????????????0???? $? ? ? ?$

Orthosuchus

$21100001301 ? 0001001000[01] 10000010001000 ? 000 ? 002011001111100 ? ? 1 ? 1 ? 03011 ? 0 ? 0 ? 0$ ?001000100011100000?120010013021142101?10?10?100000001?0101000001?000?0???00 001??0000???1010000001?0?100000?0????0??000?012?000011110?0001000?0?000?00?00? 0?0??0?000?0???0000?000100?00???100110??01?0??0?0??0?0?000??????0?00??00?????0? 0000000?00?0?00?100001??????0???????????0?00?000100????0?0?0????0????????0??00?? ??00??????0000?0???????00

Edentosuchus 201?????[12]????0??[01]0??1?0100??0?????02?110?00?????????????????????[23]?211????1 0?01010????????[234]??????????0???1[23]?????????00110??1?01?11??1000110?11?1???? ????01??001?1?1?00[01]????0????00?0?0????1??0?101??1????11??0??1??00000??0???0??? 0?????0???0?????00?0??0?1?0?00????10?101???????000??????????????????0??00?0??????? ????????????????????????????????????????00??00???0???0?120???????????????0000???100 ????0??????????????0 
KayentaForm

[12]01110?1200000?10010?0??00????0?0???11110?002010011111100001011?3011?000210 0?1010??0????00??0?12001011001112????0????01100?00?01000111?[01]01001?01?10100 000010??01?1?????????1?????00???0????1?00010112??00011??0?010???00?????????000?? ???0?????????????0???1???00????[01]?1???????????????0?????????????????????????????? ????????????????????????????????????00?0?????0???????????????????????????????10???? ????0???0????????

\section{Zaraasuchus}

10?????????????1?01?01?1000001?10?02????????????????????????????3?????0??010?????? ????????[1234]0??1010??0???????????0??????????????????????0?????1??1?????????10???? ?????0000???????0???0????0?????1?????1?00???0???0???11111111111?????????????????? ?0?????00???????????0?10???????1000??00???????0???????????????????????????????????? ???????????????????????00??0?01????????00?????00000000??????????????????0???????0? $? ? 0 ?$

\section{Gobiosuchus}

$101000 ? 110000011001 ?[01][01] ? 1 ? 00001 ? 10 ? 0201000 ? 0020112011111000 ? 0 ? ? ? ? 301 ? ? ? 0 ?$ $10100[01] 010 ? 0 ? 1 ? ? ? ? ? ? ? 0 ? 1010110[01] 3012002 ? 0000 ? ? ? 0010[01] 00001000000 ? 00001001$ 211?0100???11000000001?00000?1?0020000000???00?0?01?0121000011?00?00?00111111 $111119000000 ? ? 00000000 ? ? 0000 ? 00010 ? ? 00 ? ? ? ? 001 ? 0 ? ? 1 ? ? ? ? 10 ? 0 ? ? 0 ? ? 0 ?[12] ? ? ? 0000 ? ? 0$

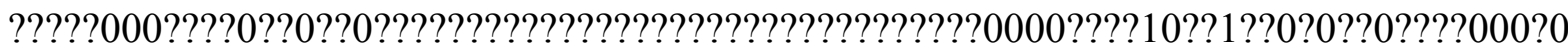
0000??000???000???0??000000??0??0?? 
Sichuanosuchus_shuhanensis

[12]01??0?1200[01]00?10010[01]1?110???1?00?021?10100020?1?011?1100???????3?11??0

?1?000011?1??1?????000????????10?11?0?1???0??100100??1??10?0????0011?[01]1210??1

0?????1??000??00100?00?10???000?0?00???0?00110?111011111100?101000010011???0??

?0?00??000?0?00????00??001???00????00??0?????0??000??00?????0????000?????????????

???0000?0???????1????????????????????????000?0??1100???0?01????[01]???0?????0??000

???000????00000??0??0?????

Sichuanosuchus_huidongensis

201??0?120??00??0?1?10?110?001100?021?10?0002?????1????0???????03?11100???00?01 1?????????????1??????1???1?0??????????0??0?????1000????00111012?????01???01??000 ?00??00[01]???1?0??00000?00???0?00?10011???11?1?001?01??001001100?0?0?0000???00 00000??0000?0001?0?00????01??0???????1000??0??????0?00?000??????????????????????? ???????????????????????????????0???0?[01]1??0???0???????0?????????0??000???000????0 ??0???0???????0

Shantungosuchus

2?1????1?0???0?1??1????11??????????21?1[01]100020?1?011?1100?10????????100?1?000? ?10???????0?????????????0?1??????1?????00100??????00??10?00???11211??101??????000 00000??0????1???10?00??0????0??????0??10111111?0?1[01]10??0???1??????????????0??? ???????????????0??0????????????????????????????????????????????????????????????????? ????????????????????????????????????????????????0???????????00??????0????????????0?? $? ? ? ? ? ?$ 
Zosuchus

201??0?1200000??001010[01]110?001110?02211010022?1??011?11000?0?1?0311110????0 ?01111??????????????????10?12?3???1?????00100011011?0001?0?0010112?[01]?0101?? ?0?0?00100010000?[01]111????0??0?00???000?1000111??1011?101101000000100???0?00 0?000?0000000???00?0?000100?00????10?10????0???0?0??00????0??00000?????????????? ????????????????????????????????????????0?00???0111??1??0???????0?????????0??0?????0 00???0?0000000???0????

Hsisosuchus_chowi 201??0?110??00?0101000[01]?1000110001021110100021112011?10000?0?1?03??11?0100 00201??????????????????????0001110??0??????01??110??100??0??000[01]11011?1?0?01?? ??10??0???0??0010???0????0000?010000?00110?1000?0001?100100[01]0?00000????0?0?0 ?00??100??000??000000001?0?00????00??0?0??????00???00?????0?00???00?????????????? ???????????????????????????????????????00??000?10????0?0???0?0?????????0???00???000 ????0??0??00???????0

Hsisosuchus_chungkingensis 201?0???????000010100001100011000?021?101000[12]??12?11?10000?0?1?0[23]?111?0?0 0[01]02?1??10???????000?1000???0?01?1021?1?????01001?????0?0000??000?1011?1??001 ????10???0??0??0010?010???000?0?000000?00110??[01]00?00011111100[01]?0000?0000? 0???000?0?10??0??????000?0001?0?00????00?00??????01000??00??????????????????????? ????????????????????????????????????????????000?0001?0?1?????10???0?01101000?????0 ???00??????00?0??????????0 
Fruitachampsa

201??001200100010000100100000110010221111?0120112?1???0?0??0??1?3?21?????[01]? 0011101011?1?00011112?0??1?0??[01]00??1?100??001?0?0100100??101?0011?01110??0? ?00?10?????001?00?0????001?0000?0????0????110???000????101??0?00000?000??0??00?? ?0??00?????????????0?100?00?????01?1??????????0????????0????0??1?????????????????? ?????????????????????????????????000??0?01????000?000?????????????0??0?0?0?00???? ??0000??00????0??

Uruguaysuchus 201?00?102??00??10??1??111??1???01022?10100011????11?1010??0???0[23]11121[01]10 00120100??1?2??1[12][1234]000?0?0??010?1100210?00??001[02]0110101?00??001?0111? 0[12]??0?011???01110000101?00?0??100?0?0000?000110101?110??0?00001?10010??000? ??00???01[01]??00?001?00?000?0??0?????10??00????0?1?0??1?110100011000?1??0???00? 0?10??1??1?????????????0??????????????????????????????00?00????????000?000110000?? ?10?00?0000?00000?0?00000?00?00??0???

\section{Candidodon}

201??0?102??0011100010[01]110??11000?022?101000?1??201??1000?10?1?0??112??????? 21100????????????????????11?1?01??010????010011?1?100000?0100?10001???0011???0?0 ?00??101?0?1011100?1?0000?0001?20001[12]1010010??01?100?000000000?????0?1?0000 001000?0?0?00?00?000100?00?????0110??1?????000000??????0?0000000???????????????? ???????????????????????????????????0?00???02???1[01]00?0?????????????????0000?0010 0?0?00001000?00?00??0 
Libycosuchus

201000?102??00??10?010?1???011000?0?2?101????11120?1?10?0??0???0?011??110001?1 000????????????????????1[01]02010?????????01?011???????????1?011?00??1???01?????0? 000??01?00?01?1?0???0000?0???0000?011010????001?100??01??????00???0?[12]00?????1 ?[01]0?000?????0??00?00?0?????00?10??1?????0????00??????0??0?0??????[01]11??????? ??????????????????????????????????????00?????????1??0???????0?001010119?00????????? ????????0?00??0??0

Simosuchus

$10301011000000100010111110 ? 0110001021 ? 10100011 ? 12011 ? 1000010 ? 1 ? 0301121110100$ 20000???????02100?2010?1002[01]2010??01??????110110121200001010011100211000201 $1 ? 210 ? 00001010001011100 ? 0 ? 0000[01] 0 ? 11110011110100100111 ? 1000100000000100000$ 21000000?10[01][01]0010??00000000100?0010??00100?0100??1000??00?0?1?0?000?0?01 0?1???1?10000100011000110001???????[01]???000101120?01[01]0[01]0011021000??0?11 $0[01] 1[01] 00101110110 ? 1000 ? ? ? 000 ? 0 ? 00000000 ? 00000 ? 10$

Malawisuchus

$101 ? 00 ? 1120000 ?[01] 10001[01][01] 1100 ? 110001 ? 22110100011 ? ? 20 ? ? ? 1000 ? 10 ? 1 ? 03 ? 111[$ 01]1?0100211001????1??2100000?0??01112111??01?0???01100101?11000???100110101?0 ?0001???0?01000?101000001?10??1?00?0?000012?00121110?1000?11100000000000000?? ?0?[01]?0?00001000???0????00??001?0?00????00??0??1?0??100010000??????0??000?1???

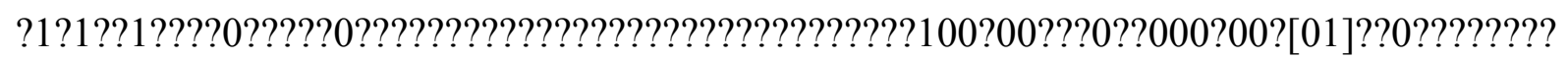
?????00???100?0??0000000?00???0?0 
Pakasuchus

$101 ? ? 0 ? 1 ? 21 ? ? ? 1110001011 ? 1 ? 01100010221101000 ? ? ? 12 ? 11 ? 1000 ? 10 ? 1 ? 03 ? 21111 ? 01002$ ?110????????1?0??000???0??11?13??01?????01100??????000000?001111011?00001110010 $1000 ? 101001 ? 01 ? ? ? 0 ? 1 ? 0000100001100 ? 1211100100001 ? 100 ? 000000000000000 ? ? ? 000 ? 00$ 110???????0??0?0001?0?00?????0??0???????10000000???????00?000010???1????????????? ??0???????0111????????????????????10????02???0000?0??1??0??0?190119???00???100?10 ?000?????00??????

Chimaerasuchus

10120001121?00??????????????????????????????????????????????????11??0?10?01?10??1 ?0?????2100??0????11?0?31421??00??10?211111011?00???1?0110???????????0011??000?? 00???????1?????0????0????[01]????1???????????1?0?????0?????[12]??????200000????00?0 ?0????0?????10???0???1????????0??????0??????01000???????10???001?0?001??001???????

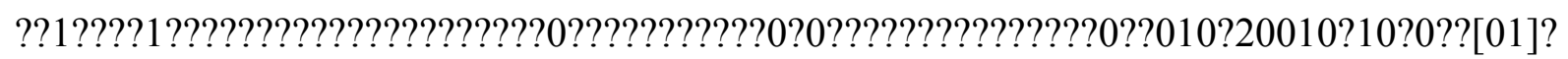
$0 ? ? ? ? ? 00 ? ?$

Notosuchus

$101 ? 00 ? 1020100111000111111001100[01] 1022110110021112011 ? 10000 ? 0 ? 1103111111 ? 0$ 1001100011112?1?2[01]0001000??01112012??1100121[01]1201[01]0100100000011111111 $11 ? 00011110010100000011000011100 ? 1 ? 001000 ? 1110001121010110001111011000000000$ $00000021010[01] 01011[01] 10000 ? 00000 ? 0001000000 ? 0100100101 ? 1 ? 010000100000 ? ? 0 ? 0$ 00100010?10111?1101?110010?0111?11101111?0001?100??????0??000000012101[01]001 $00102101 ? 101100111 ? 00011 ? 0000 ? 1100000000000100000$ 
Comahuesuchus

103??0?102??00?????0111????????0010?2????1?011?1?????????????????121??????0?1[01] 101????????????????????0??[01]13??1??????0000?101201[01]01?????011??0?1????11???1 $1 ? ? 020 ? ? 001020011 ? 0[01] ? 1 ? 0 ? 00 ? 10119000 ? 111010 ? ? 000 ? ? ? 100 ? ? ? 00000 ? ? 0 ? ? ? ? 0 ?[12] 0$ 1[01]1110?1[01][01]0000?00??0?000100?00????1?110101?????00?01?0??1????0??1?0????? ????????????????????????????????????????????????0???0001?????[01]00?0?22?1?????????? ?1?000?00000?0????00000?001000??

Mariliasuchus

$101 ? 00 ? 10200001110001[01][12] 111000110[01] 102211 ? 110021112011 ? 1100010 ? 1 ? 031211$ 11101001100011?1????2?00?0002??0?1121132?110?1??0020[01]1010010??[01]0010[01]11 $110110 ? 00111 ? ? 0101000010100[12] 0011 ? 00 ? 1 ? 0000[01] 0 ? 11100011211100100011 ? 10100$ 000000000000002[12]011111011010000?000?0?000100000????10000?[01]101?0?000010?? 001???0001100?????1?????????????????????????????????????????????1110111121011001 $000121111101101111100111100010110000[01] 000000 ? 00000$

\section{Labidiosuchus} ????????????????????????????????????????????????????????????????????1????0????0???? ?????????????????1??????????????0?????????????????1???????????????01???00?0?????? ????????????????????0???2???????????????????????????????????????????????????0??????? ????????1????????????????????????????????????????????????????????????????????????? ?????????????????????????10?01???????????????01???????10???????????????????

Caryonosuchus 1?1??0?10???0???????????????????????????????????????????????????????????????100???? 


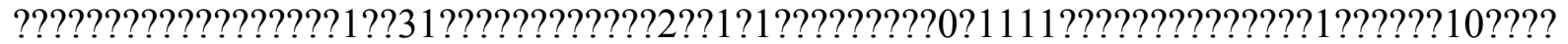
????????1?0????0????00???????????????????????0????????????????0????0??000????????? ?1?????????0??????????????????????0???????????????????????????????????????????????? ????????????????????????????11???????????????0??1111??001111????0????????????

S._huenei

101?000102??00??100?????110?????????21101?00???1?011?1100??0?????12?[12]???????? 100?????????????????????01?[12]312???0??????21111101111111110111110011101111?0? 10??0??100??0?0??????1?00???0????00??1?1??0?10??11??0000000?00???????0?10?010??1 ?00?000?00?0?????10??000???0?1????10????0?001???0010????0?101???????????????????? ???????????????????????????????0??01????2??0[01]011????????????????0?011111?00111 101010?00?0???00??

Armadillosuchus

101??00102??00?110001011110011001102?????????111??11?11000?0????3?21?????????10 00???????????0101[011????1?231????0???????2?1?11?11?1?1??00??11100?1??111??????? ????1000001011?0??1?0??1?0????0???1???10?1???1?110?0010000000??00?0???10??????? ??00??0?00?0001?0?0?????[01]0?000??0????000???0??0?0??00???01??????????????1?00??

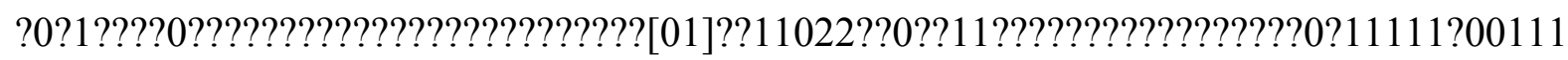
$1 ? ? ? ? 00 ? 0 ? ? ? ? 0 ? 01[01]$

Caipirasuchus.stenognathus $101 ? 00 ? 1020000 ? 11000111111001110 ? ? 022110110021112011 ? 11000 ? 0 ? ? ? ? 311111110100$ 11000????????????????????1112112??11?????002011010110111001?1111101?010111???01 0?0000101000001?100?1?0000[01]0?11100011211100100011?10[01]100000000000???020 
011101011000000?00000?000100?00????[01]00?0?0101???000?100?00100?000100??????? ??????????????????????????????????????????????001111?121010?01210121111101101111? $111111100111101011000 ? 001 ? 0011$

Caipirasuchus.montealtensis

101????10200?0?11000111111?01110????21101100211?2011??100??0????3?1111????0?11 000???????????????????01?2?12??11?????00?01??1?1101[01]?00101111?01?0??111???01? ?0000?01000?0??100???0000?0?11?0001121110010??11?100?000000000?????010?101010 110000?0?00000?000100?00????0?[01]10?01?0???00001??????00?00?1101?????????????? ?????????????????????????????????????0??1?01121?1?[01]012101211?0????????1?111????? $00 ? ? 11010100000001 ? 00 ? 1$

Caipirasuchus.paulistanus

$101 ? 00010200 ? 0 ? 11000111111 ? 011 ? 01 ? ? 221101100 ? ? ? 1 ? 011 ? ? ? ? ? 0 ? 0 ? ? ? ? 3 ? 111111010 ? 11$ 000???????????????????01?2112??1??????002011[01]101101[01]?001?1111101?????11??? 01??0000?01000??1?10[01]???0000?0?11?00011211?00100011?100?0?00000??00???01001 0?01011000000?00000??00100?00????0?0?0??10????000110??00100?000100?????????????

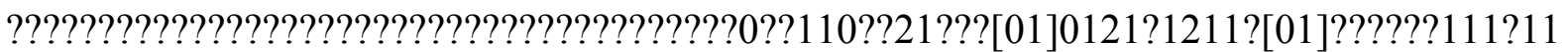
$111 ? ? 00 ? ? 1101010000 ? 000 ? 00 ?[01]$

Yacarerani

101?00?102??00?1100010111100011011022110110021112011??1000?0?1?03121111?0000 11000?????????????????????112112??11?????00211101001011100101111?01???0111???01 0?00001010000011100?1?0000?0?11100011211101100011?10000?000000000???02001011 1011000000?00000?000100?00????10000??100???0001100?0010??0001001????????????? 
??????????????????????????????????????1110?1112001100101012111110110111101100?11 $01111101000000010 ?[01] 0010$

Adamantinasuchus

101??0?10???00??10?0111111??111?????????????????????????????????[12]1?1????0??10 00?????????????????????1??112??1??????0?2[01]0101?01?0????1?1111?01??????????01??0 00?101??00???1???1?0????0????0????2???????00????0??0??0001??0????0?0??111????00?0 00??00?0????1?0?00????10??0????????000??0?????0??00???0??????????????????????????? ?????????????????????????????????????????10111?????????????10??00?1101?????1000??? $0 ? ? ? ? ? 0 ? 0$

\section{Coringasuchus}

1??????????????????????????????????????????????????????????????????????????????????? ??????????????????????????????????????????????????1?????????????????1+??0?????????? ???????????????????????[12]?????????????????????????????????????????2??????????????? ????????????????????????????????????????????????????????????????????????????????????? ??????????????????????????????????????????????0?????????????????????????????

\section{Morrinhosuchus}

101??0?102??00?????????????????????2?????????????????????????????1?????????11000??

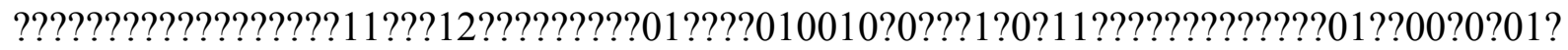
??????1?0?1?0????0?[01]1?000??2??????0??????0?????0???????????[01]?1???????00?000? [01]?00?????10???0??????1????????????00???????00???0????????????????????????????????

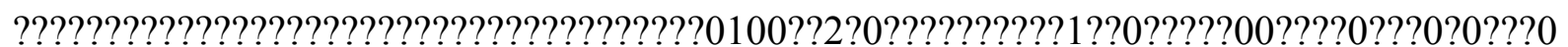
??00?? 


\section{Campinasuchus}

1000?0?132??00?1101?11111100110011032110110121???011?1?00????????021111?00011 111??????????????????????202103???1??????101110101111100?110111102?0?0?11???[01] 10??[02]0?000?00101110????0011?001100?001110?01100011?100?0000?000000???0?21[1 2]000111110?000?00?00?000100?00????001?0??1?????0?00100?00?00??111100?????????? ??????????????????????????????????????????01????121?1?110?0??1??0??0?10?110?0000? 00000?0??0?11??10?11??10?

\section{Pissarrachampsa}

100??0?122??00111010111111?0110011032110110121112011?10000?0????3?211??????1 ?11?????????????????????2?2204??01??????1011?01?1111?001?10?11102?[01]?0011???[0 1]????20?0000001011?01?1?00111000[01]?0?001110?0110??11?1001000000000?????0?2? 10001111110000?00?00?000100?01????00110?11?????00001?0???????0111100??????????? ????????????????????????????????????????0?10?00?210?1110?0??1?1?????????0??000?0 0000?0?0011111101111??[01]0

B._albertoi

1??????????????10?????111????????3???????21??201??????????????1??1??00??????1 1102?1?2100?00?20?0??0????21??001211??11???????1??01?10???1021????11110???1??0?? ????0101????????????????0????10??10?1?00??1????000?00000000000?????0????????????? 00???000???0??0??1?0????1???1010????000???????????0011110011?101?11111100?01101 1101111?000?01??1110?000??010???12??????????????0???1?0211?????????????????11???1 1??????1? 
B. pachecoi

100??00132??00?1101????111?0110????32?10110021112011?1000?10??10??21111101011 1111???????????????????202103???1?????1101110101[01]1110011101111021[01]?0011? ??[01]00?1200?00?00101??0101?001??000[01]001001010101?000?1?00010000000?000??? 0?2??000111110?000?0000??00010??0?????001?0?1?0????0000200??110??0?11?00??????? ?????????????????????????????????????????????00?0???1?101?100?02019100?????2110?00 $00 ? 00000 ? 0 ? 0 ? 101 ? 1111 ? ? ? 0110$

B._salgadoensis

$100 ? 00 ? 1320100 ? 110101[01] 111100110011032110110021112011 ? 1000010 ? 1 ? 03121111 ? 00$ 011111111????1?2?0000002000?2021032101?012?11011101?1111?001?101[01]?102?[01]? $001 ? 110[01] 0011200000 ? 001011 ? 01 ? 1 ? 0011 ? 00010010 ? 101010 ? 100011 ? 000 ? 00000000000$ ???0?2120001111100000?000?0?00010?001?0??00110?[01]????010000200?0??0?001?1100

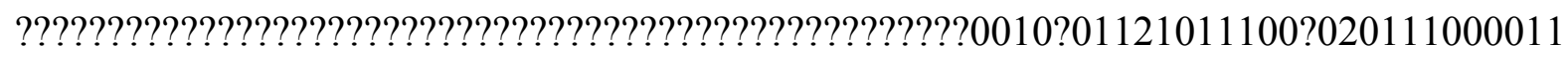
$02110 ? 0000 ? 00000 ? 0 ? 0 ? 1012 ? 1111110110$

Stratiotosuchus

100?00012201001?101[01]11[12]11100110011032110110121?12011010000?0?1?031211?? ??001[12]111????0211???00?????????2?22032101?0?211101110101111?00?1100111[01]21 1?0011?1??001??000001001011?01?1?0011100?100?001010101100011?100100001000000? ??0?2020001111100000?000?0?00010??01????0?110?110?1??000010000110?00111100???? ???????1011111100?1110111??????00010101101[01]200??00[01]0?01120011110?020??10? 0????2110?0000?00?00?0?0?11?21111111?100 
Pehuenchesuchus

??????????????????????????????????????????????????????????????????????????0?[12]??00?

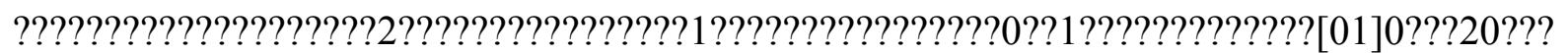
????????????????????????00???0?????????????????????????????????????????????????????? ????????????????????????????????????????????????????????????????????????????????????? ??????????????????????????????0?0?????????????????00?????000????????????????????

\section{Cynodontosuchus}

??0?00?122?????????????????????????2????????????????????????????2?????????1011??? ??????????????????2??1?3??????????1?????1???1???????0011?????????????[01]???????00 ????????????1?????[01]?00??0????0??????0??????00????0????????????2????0?????0?000?0 ?????????????????????????????????0????01?0????????????????????????????????????????? ????????????????????0????????????100?0????1??????????0??00????????????????0??01???1 $? ?$

\section{Bergisuchus}

1?0?????????????????????????????????????????????????????????????11????????????10???

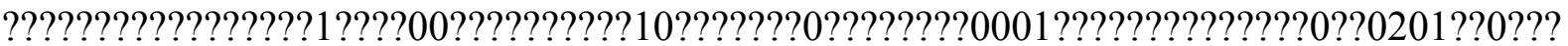
??????????0????0????0?0??0?????????????0?????????????????????????????0????????????? 1???????????????????????????????????00????????????????????????????????????????????? ????????????????????????????0???????????????????0??????????????0???????????

Iberosuchus

$1 ? 0 ? 00012 ? ? ? 00111000111111 ? 01 ? 00 ? ? 02 ? ? 101 ? 0 ? 11 ? 12 ? 11 ? 1010 ? ? 0 ? 190 ? ? 111 ? ? 10 ? 0 ? 10$ 11011??????[12][1234]00??00???0?2?[12][01]0?2?0000???1101110101??1?0??100001001? 
0??001???[01]000?201000100101??0101?01?100000?0[01]000010101?0??11?100[01]00100 0000??0??0?212000?01?10?000??00?0?0001???00????00??0???0?1??[01]0????00010[01]0? 00??[01]00111??????????101[01]01110?????????????11011??????????????00?0?02???1??0? 0??1????????????0?0000?0000???????100?0??01?00??

Bretesuchus

100?001122??00???????????0?????????2?101000?????????101?????????12?0111?1001011 0????????????????????2??100????????1?0???0???011??0???0001???????????[01]11?120 [01]010?????????1?1?01???00???010??01???0?000?1??00?????????11?????212?001?1010? 101?[01]?0??????10??0?????0?1????0?????0??010??0?2[01]????0?1??????????????????????

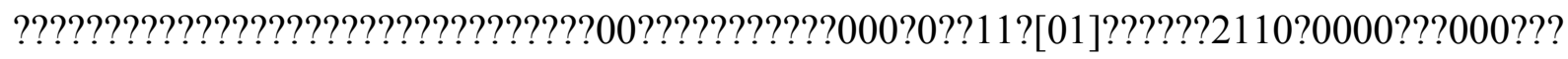
$0 ? ? ? 0 ? ? ? ? 0 ? ? ? 10 ? ?$

\section{Barinasuchus}

?00000?12???00??????????????????????2?101100?????????????????????12?0???????1[01]1 1?????????????????????2??[012]00??????????100?????11????????0001??????????????????

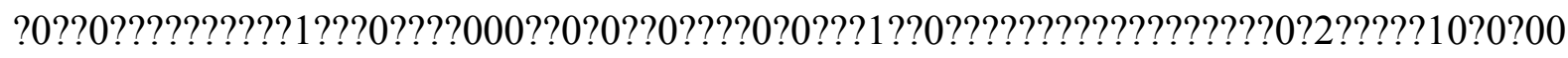
0??????????1??????????????????????????????????0????1?????????????????????????????? ????????????????????????????????????????????????????????????0????0????????0?+???0?? $? 0 ? ?$

S._huilensis

???????????????????????????????????????????????????????????????????????????????1????? ??????????????????????????????????0????????????????0??2?????????????????120???0????? ??????????????????0????0???????????????????????????????????????????????????????????? 
????????????????????????????????????????????????????????????????????????????????????? ?????????0?????????????0?0??????????????????000?00?00????????????????????

S._icaeorhinus

$100 ? 0 ? ? 1120000 ? 1100011[01] 110 ? ? ? 100[01] 1022 ? 101100111120111 ? 0 ? 0010 ? 1103 ? 210 ? ? 1$ 0?00[12]0110??1?21??2400?????????[23]01[01]0021?000?2?1?001??????0???00?00002011 010??01??0[01]1101[02]0?1?0?0110[01]??0??1?010??00??00???00?01001000011100?001?0 000011???0?0?200??0101??00??000?0000010?000?????0??0?1??????0000000?01[01]1?100 00?00111100011??0?1?110101011101??00111011111101111021000?0000000???01000?0?? ??????1?0??1?0??000?00000???1?010000?0?1??0??

S._querejazus

100??????2????1?1??011??10??????????2?101000???????????1??????????2?1?????????[01] ???????????????????????????00???0???????001?????10???00??0002?[01]???0???????????? ???????1??????????000?[01]00???0?????1???0?0??01??00??????0????????????200?00101?? ?????0??0????10??00????????????0??????00????????110000????????????????????????????

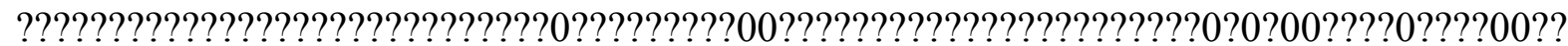
$0 ? 0 ? 0 ? ? ?$

Ayllusuchus

[12]0[01]?0011[12]2??00????????????????????????????????????????????????????2???????? ??[01]1?????????????????????????[01]0[012]??0??????????????0?1????????000[01]???????

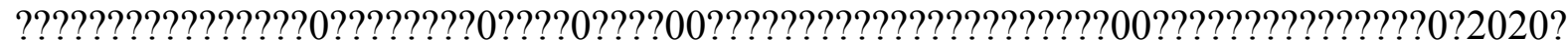
0?????0??????????????10?????????????????????????????12??1?????????????????????????? 
??????????????????????????????????????????????00??????????????????0??????????????0?? ?0?0??????10??

\section{Lorosuchus}

1030121112??001?100011[12]10[01]???10?????2?10100011????1??1??00?0?1???0211?1?0 1??201?0?????????????????????301100??????????1101??101101????0?001101[01]?1???01? ??[01]01???10100??0??1???1?1?01??000??000000010?00?0?0?1?100?0010?00?000???0?00 2?00??1010?000?00???????10??00??????111??1?0????0?0?0??0111?0?0001?0???????????? ???????????????????????????????????????00?0?0???????000?0??2??0?0110?0110?0000??? 000???0?000000?000?00??

Lumbrera_form 100?00?112??00??1??011?1?0?0110?0???2????100????????????????1?03121[01]1?101001 0110?????????????????????2?1?0[01]?????????1??111??1?110?????0?0002011?1???0????[01 ]11?1200?00?011?1???0???01?1?0000?010??0??10?10000??100?00?0?00??11???0?0?2000? ???1??000??00?0?0?010??0?????0???0???????000010??????110???0???????????????????? ????????????????????????????????0000?0?02????000?0??1??0?????????0?0000?00000???? ???0?????00??0?0

\section{Pabhwehshi}

??0?00112???00??????????????????????????????????????????????????211????????11[12]1 ?????????????????????2??20??????????10??10101?????????0?11????????????[01]??????

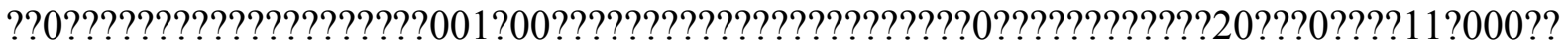
????????1????0??????????????????????????1?0??????????????????????????????????????? 
??????????????????????????????????0??????1??????????0?000??00??????????0?????[01]?? $10 ? ?$

A._gomesii

$201000 ? 102000011100010111110111001022110100011112011 ? 10000 ? 0 ? 110301121110001$ 201[01][01]1[01]11211?1[234]00010001001001100210100111010010010[01]100000010011 10021000?110?00111010?1010021001100?10100011000101[01]1101011010000111001000 00000000000010000000010000000?000000000100000??0100?101?1?111100000000?1??0? 000000110111[01]1[01]11010?00001100??????101111000000??1001?200??0000010020001 000?00011?00011010100?0000?00000?0??0001000?0??00000

\section{A. patagonicus}

$201000 ? 1020000 ? 1[01] 000101111 ? 0111001022110100011 ? 12 ? 11 ? 1000 ? ? 0 ? 1 ? 03 ? 11211 ? 00$ 012[01]1??1?1?????????1000??01001100??01???1?01?01101?110000??100111[01]02?0??0 1????0???0??0?0?0011001100?10[01]000?000110?0111101101000[01]1110?100000000000 000010?00000010[01]00000??0?00?000100000?????0?10??1?111?00000000????0?0000001 ???????????????????????????????????????????????????000?10[01]200?1000?[01]001???? ?11010?0???000???000????0?0?000?0??0??00

\section{A._buitreraensis}

[12]01????1?2???0??10001?0111?0110?0???211010001????????????????1?[23]?112????0? ?2?10?????????????????????[01]???0[0123]??0???????1??1??10?100??0???0?11?02??????? ???01???[01]00?0?1?1?0????0?1?1000?10[01]1?0?01?[01]10??110??01?1?0?0????00?0???? ?02??0??000100???????00??????00??0????0??101???1????0?00????1??0???0010???????? 
????????????????????????????????????????????0????????????000?0001?0?????????????00? ???????????????0??0???0??0

A._wegeneri

201??011021?00111000111111?0110001022110100011112011?10100?0?1?03?111???0???2 01???????????????10001?010?1000???1??????10011010110000001001110021[01]00011??? 01???10?101001100110??1?10001100??0000101011010??01?1001001000000??0000?10000 00010000000?000000000100?00????00100?0110??100000???01100?0000001????????????

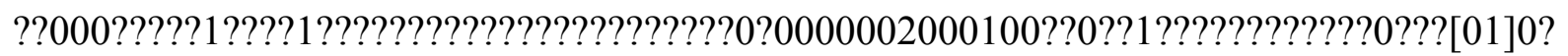
00000?0000001000?0?000000

A._tsangatsangana $201 ? 00 ? 1021 ? 00111000101111101100010221101 ? 0011112011 ? 1000 ? 10 ? 110201121110001$ 201011111?1?01300010?0???100100021010001101101001??1000?00000111102100001101 ?01?1?10010100210[01]??01?1?10001100110000101011110000111001000000000?00??0?0 0000[01]0?10000000??00000000100?00?0??00?1010??011?000??000?1??0???0????111??[0 1]1111?10?0000110?001000?01111?0[01]0?010??????00010??????0?0???000?0??2?000?11 0??1?0?0000???000???0?0?1?0??0???0??0

\section{Anatosuchus}

203000?10210001110?011111??011000102211010?011????11?10100?0?1?0?011111?00012 010?1???????[01]?00?10001?01001000?101????1?1101001?100000????0110002?[01]??01? 0???10???0??0?00210?010????1000[01][01]010?0?00?0?01101000011100[01]000?0000???0 000?0?00000011?00?10?0??00000010??000??1?0?10?01?0?11??00000?????0?00?000?????? 
????10???????1??0?????????????????????????????000??000200010?0?0??1??0?011010100 ??000???000????0001000?0?1?0000

Montealtosuchus

201??001221?001110001001110011100102211010001111201111010010?1?03?1111210000 1011111??????1[234]00?10[12]0?10100110021010???111001?010100000001000110011100 ?01??0011?03001000011010100?1?00001[01]001000000010100100001?100000[01]110000 010??0??0000000100?0000?200000000100?00???100[01]1010110??10001000?11110?0000 000?????1???1010?0??0?1????????1???????????????????????0000000020011000?01111[01] 00011010100?0000?00000???1?00?000?0???0000

Uberabasuchus 201000?12?1?00??10001011110011000102211????0111????1?????????????[23]011?12?0100 1011????1?1?????0?1020??00002000210??0??111[01]01101?10?00????00011001?1???0??? ?001???0??0?001100?10????0??0?[01]00100?0??0??1??1?00??1100?00?110000010??0?2?0 000????010000??0000?0001?0?00?????0??0???????1000??0??1??10?00???01?????111????0 ????????0??????1????????????????????????00??0002????0?0?0111??0?01101910????00???0 00?????000??0??????0?0

\section{Lomasuchus}

201????1221?00111000101111?0110001022110100011?12?11?10100?0?1?03?111?2??000? ?111????????????????????1?01?00??0100?1?0?001??10100000???00011001110000?????01? ?30010000?1?1010??1?0000?[01]0??00?000010100100001?100000111000001???0???00000 0100?0?00?200000000100?00?????0[01]101???0???0001000??1??0?000000????????1?1?10 
00000??0????????????11?0?????101102????000000002?01100????1?????0110??10?????0?0 000????1?00?00??0???0?00

Gasparinisuchus

20[123]?00?1[12]2??00??????10[01]1???????00???2?10???0??????????0????????????1????1

?0??0111?????????????????????00?000??01??????1001??10100?????0?001?????????????[0

1]01?03?0?000???????0??1?00???[01]0??0000??0??????0??????000???1??????????0???0?00 ?0??0?0000????????0010???0??????????????????0??????1???????????????????????????????

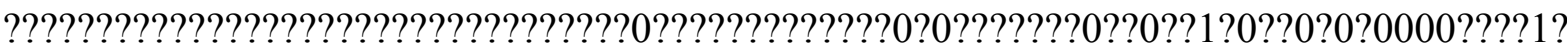
??????????0???

Hamadasuchus

20100011[12]20000111000101111?0110001012110100111112?1111010010?11?[23]0111?? ?????[12]1211????????????????????1??1100??01??????100110111001000000001100111000 01???[01][01]1?130?100001100010??1?00001100??0000001010010??01?1000001000000?? ???0?0100000010010000?200000000100?00?????[01]10?01?0???00010?0?01110?0000001 ????????????????????????????????????????????????????1?000000200?100???????????????? ??0???00???00????1?001000?????1?00

Mahajangasuchus 103?1[12]?1021??01211?0101111001100010421101011011?2011?10100101110??11211101 01?01111?1121??140000000??01202[012]00?10100?11011010?121?00?0000000111021100 00????201113001000021001100?1?[01]?011[01]0??000010010100100001110000010?00000 00??020?0000001?000000???000000010??01?????0[01]?1?[01]??0?1?0001000?01?01?0000 
01?11110011?10???0000110[01]001110?0111111001?1[01]??????00??0000?0???1011000?0 2[01]???00011000100??000???0010??0?110100?1??0???0

Kaprosuchus

$10311211221 ? 001 ? 10 ? 0111 ? 11 ? ? 1100010421101011 ? 1 ? ? ? 011 ? 10 ? 0 ? ? ? ? ? ? ? 3011201 ? ? 0011$ 1211????????????????????1202200??0??????0?10?0?12?1000000?00011002?1??00????[12] 11??300?00001100?10????1000110??00?010010?00110001?100100???00?0?0???0[12]0100 0000100?0000?[01]0000?000100?01????00[01]?0??1?1???000??0??0??11??00001????????

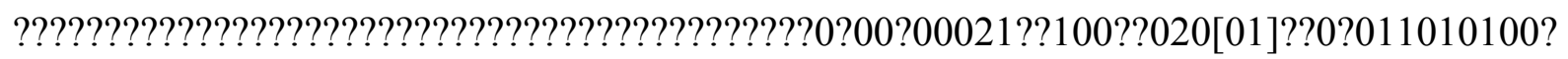
0000???00????0?110000???0?0??0

Stolokrosuchus 20100001120000111[01]00101111?00100[01]101211?????11112011?1010010?1?0??11?1?? ??003[01][12]??????????????????????1??0000??0[01]?????01101111011010000000011001? 101101???[01]11?00111000021011100?1?[01]??0[01]0100?000?00?010?10000??100000100 00000????0?010000????000000?10?100000?00?00??????11010?1????000???0?11011?000?? 02????????????????????????????????????????????????????0?0000?020001000?0??10?0???? ?????0?00010??00????0??000?0????01000

Theriosuchus

20310111120100110000110111100110011?211010001?11?01111000?????1?20111??10010 $20101101121100[234] 102120010013010002 ? 0 ? 10 ? ? 101[01] 0[01] 001 ? 1100 ? 00 ? 0 ? 00110 ? ? 0$ $1 ? ? 0 ? 00 ? ? 10[01] 00210100[01] 02 ? 00 ? 100 ? 1 ? 10001110[01] ? 0 ? ? 0 ? 0101 ? 010 ? ? 01 ? 1000 ? 0 ? ? 0$ 000?2????0?0?0???0?10??0000?0???000??100?00??0?0?0011?1??0?100000?00?????????0?? 
0???????????????????????????????????????????????????0?????00?0?01000?0???????????? ???0??0???0?00????0?00?0?0?0???0??0

Alligatorium ?03?????1?0000?1000010?111??0?100?1????0??00??11??1??1000???????20?1????00102?1 01?011211000???1?00100???????????10??1??????????????????0??????????????????????1? ??????????????????????????0???????????????????????0??????????????????????????0????? ??????1???00???????????????????????????????????????????????????????????????????????? ?????????????????????????????????????????????????????????????????????????????????

Goniopholis_simus $203 ? 1211120010111000100111 ? 0010001002 ? 101000 ? 1112011 ? 1010 ? 10 ? 1 ? 021212 ? ? 100[01$ ]0?02011?1??1??0?00?1200?11?300000210010??101101??101100?000010010001?1???0000 $1110003110001021100 ? 10 ? 101000111 ? ? 0000000101001000011110 ? 001000000000000 ? 000$ 0000?10000[01]00?000?0?000100?00??????000?????????0100???0???????0?????????????? ???????????????????????????????????????????0?0???????00?????????????????0??0110?? 00??????0?1????0??????0

Goniopholis_stovalli 203?121111??101?1000100111?0010001001?1??000?1112011?10?0??0?1?021212?110???? 02????????????????????????00100??00???????101??1?1100??000?0010001?1???00?????0?? ???0001021?00????1?1??0?11??00??00?10?0??0??01?1100001000000?????0?0000000?1?00 0000?0???0?000100?00?????0?0010?100??000?00010??0??????????????????????????????1? ?????????????????????????????0?0?????0???10????11?????????????0?0000???00????0?001 $000 ? 0 ? ? ? ? 0 ? 0$ 


\section{Eutretauranosuchus}

203????1?10010111000100111?00?0001001110?000?1112011?1010??0?1?0?121201?00002 020111???1??0??0?1???????3??000??00?????0?101????110???????0??00???1???0????11??? [012]?1??01021100?1????10?0??1???00000010?0??000?1?110??01?0000000???0?000?00?? 100?0?00??00?0??00100?00??0??010010??0???0001000?????????????1???????????????????

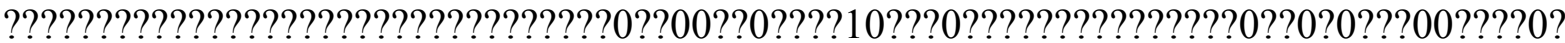
001000????????0

Calsoyasuchus

203?0201110?10?110?01021111001000?001?1???00?1112?11??0?0??0?1?0?111[12]??????? ?01??????????????????????0??0000??00???????101??11110?0???0?0010001?1???00??????? ?????001021?001?????1????01???0??00?????????????1100?0100000??????0?0000000???00 0000??0?100?0?100?00?????0?1010??0??1000???0?????????????????????????????????????? ???????????????????????????????????????00?????????????????????????????????0?0????? ???????0

Sunosuchus

203?0201111?10?1100010011110010001002210100011112011110100?0?11021212??10001 20101??1111?0?20001200?11???????????????????????????????????????????????????????? ?????????????????????????????????????????????????????????????????????????????????? ??????????????10???0??011???00?00?1000?001????????0?????????????????????1???????0 ????????????????????????????????????????????????????????????????0???????0???????????? ?? 
Shamosuchus

203????10?1??0111000110111000100010021101?101111??1111010000?110??210?1100102 ?1???????1101[34]1?[01][13]1?0?10?[03]00[012]002?00[01]????01100??1?11?0?000000010 $0011101 ? 00001 ? ? 0 ? 0 ? 10 ? 000021[01] ? ? ? 1 ? ? 1 ? 1000 ? 100000 ? 0 ? 001010010 ? 001 ? 10 ? 0001000$ 000210?10???000?0?100?0??0??00?000001?0?000??1?0?01101??00010111011?????????0?? ?0????????????????????????????????????????????????????000000020101000?01??????0010 ?0010????0???00????0?000000?????0??0

Bernissartia 203??21112??00111000?00111?001000?002?????1101112?11?10100?0?1???1?1??11001020 2011?1?21??0200111101101300000??0????????1????1????????0??0?10???01???0????1?0?? 31?100102110?1100101000111??000??0?1?????0??????00???10000??0?0??0???0???0?10?? ?0???????0??001?0?001000001?1?0010?01000?010????????????????????????????????????? ???????????????????????????????0???????????0???????????????????????????00????0?0???? ??????0??0

Hylaeochampsa 00???????21???11????1?01???0????0?002?1?1022????2????101??1??1????210??????????? ??????????????????????????????0???????10????????????0??0??????0???????????????????00 021?01???????00?1?2???0???????????????????????????????????0???????0?1???0?????????? ?00??0????????001110???????0000?0??????????0??????????????????????????????????????? ????????????????0?00??0?00[01]?1[01]0???????????????????????????????0?0??????0??00 $? ? 0$ 
Glen_Rose_Form

2030001112??0011???0100111?001100?0?2110?011??112?11?10100?0?1?030210????01?2

0211?????????????????????3??000??00?????01100??1?1?00?0000??010?0????1??????10??1

3101001021??1?10?1?10?0?1000?000??01?1?010?0?1?1000???000?0?2????0?00000000100

00000?0?0?00?00100?00????200011001???1?1?1000?011??????0????????????????????????

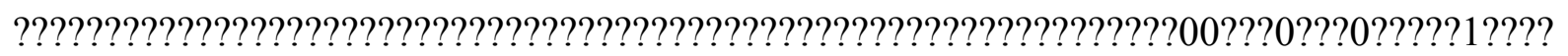

????0???0???

Borealosuchus

$203 ? 1211120010111000100111 ? 001000100211010221111211111010010 ? 110 ? 12100 ? 10001$

202011111211113111?110?11?300000210?100?00?101??11110??000000010001?1???00001

10000310?00?021101??????1000[12]11??0000?001010010000111000001000000000000?00

0???0?100??000?00??00?001000000?0100010?111?00?00000000?????????????????????????

?????????????????????????????????????????????????????????????????????????0????????0??

???0?0?????????????0

Pristichampsus_vorax

200?02?112000011100010111100010001002110??2211112011?10100?0?1?1?1210?????0?2 02011?112??0?311?1?????1?3?0000??001?????1001??1?1100?0000000110010100?000??[0 1]0??0300100002??01?1001?[01]001?1?00?000?001010010???111000001000000??0??0?00 00000?10000000?00??00000100?000011000111111????000???00???????????????????????? ??????????????????????????????????????????????????????????????????????????0?+??0?000 00?????0?????????????? 
Eothoracosaurus_mississippiensi

[12]02?1211120010??11?[01]100111?0010001002110??2?011?2??1?1?11????1?0?121???10 0??30000????????[1234]111[12]1????1?3000002?0?1?0??01?01??121100?0000?00100?1?? ???00????0000010?001021101??????0000???000000?00101?0?000?1?10000010??000?00?? 0?0000?00??0001000?100???000100?00????01010?1?0????0000000?????????????????????? ????????????????????????????????????????????????????????0????????????????????0??????? ???????????????????????

\section{Gavialis}

$212 ? 12110200111111011011111001000100211010220111201111011010111011210021000$ $130000 ? 1112110131112111100 ? 300000210 ? 10000[01] ? 101 ? ? 121100 ? 00000001000101 ? 1 ? 0$ $0001 ? 00000100001021101 ? 1 ? 0100000[12] 1 ? ? 00000 ? 001010010000111000001 ? 0000000000$ 0?000??00?10001000?[13]00?000001000101110010110110?001000001000?1??????????00? 01000????0????????1???????0???1??????????????????0000000100100000?0[01]000?000110 00000?0000???00????0?000000?0??00010

Leidyosuchus_canadensis $203112111200[01] 01110001001111001000 ? 0021101022 ? 1112111110100 ? 0 ? 1 ? 0 ? 12100 ? 100$ 0120201?????????????20???10?300000??00?????01101??111100?00000001000101?1?00??? 1[01]???31?1001021100?1001?1000211??0000?0010100100001?10000010?000000???0?00 00000?10000000?000?00000100?00???1001101111????00010?0?01??????????1??????????? ?????????????????????????????????????????????????????100??????????????????0????????0 0????0?0??????????0??0 
Asiatosuchus_germanicus

203?1211120000111000101111?0010001002?10?022111?2?1??1??0????1?0?12100??00012 0?012?1?21??1?11????????300000?10?????101101??1[12]1100????00001000101???000?? 10000?10?001021?01?1????10?0?11000000?0?1?1001000?11100?0010?0000?0???0?00000 00?12000000?000?0?000100?00101100010?111?0??000?0000???????????????????????????? ???????????????????????????????????????????????????????????????????????????????00???? ?????????????????

\section{Crocodylus}

$203012111200[01] 011100010211110010001002110 ? 02211112011110100101110112100210$ $0010020121112110131112021100 ? 3000002100100000 ? 101 ? ? 121100 ? 0000000100010101 ? 0$ 0001?00003101001021101?100111000211??00000001010010000111000001000000000000? 0000000?10000000??00?000001000001011000101111?00100000000001?????????00????00 $0000000000001010001001000010000000100001101 ? ? 0000000000101000 ? 0[01][01] 00 ? 000$ 11010100?0000???00????0?000000?0??00000

Diplocynodon_hantoniensis 203?1211120010111000101111?0010001002110?02211112011110100?0?110?12100?10001 $0020111112110131112021110 ? 3000002 ? 001 ? ? ? ? 01101 ? ? 111[01] 00 ? ? 0000001000101 ? 1 ? 00$ 00110000310?001021001?10?1?1000?11?00000?00101001000?11100?0010?00000000?0?0 000000?100?00???000?00000100?000011001101111?00100011000??????????????????????? ???????????????????????????????????????????????????????????????????????????0????????0 0????0?0?????????????? 
Alligator

203112?102?0001110001021111001000?00211010221111201111010010111010212011000 $10020121112111131112021100 ? 30000021001000001101 ? ? 111000 ? 00000001000[12] 1101 ?$ $000011 ? 0003101001021000 ? 100111000211 ? ? 00000001010010000111000001000000000000$ ?0000000?10000000?000?000001000000011001111111000100011000011?????????1000010 $00000000000001010001001000010000000100001101110000000[01] 10101000 ? 0 ? ? 00 ? 0101$ 1010000?0000???00????0?000000?0???0000

Pelagosaurus

202?[01]111?20011020101[01]00000000000[01]1002110100000011011?1001001?10001101 ?100000300001101?1?00000012000111?011002100????01?101??1??10000??00001010110? ?[01]00???100000??0001101000100?100200?0??0?0?00001011010000110000001??000000 0??0???20?00?10[01]000000310001100110?00??????1000?1????10000000?????????????1?? ?0?????????????????????????1?00???????????????????0000?00?00?000?0?010???0???????? ?0?0??????00????0?0000?0?0???0000

Steneosaurus_bollensis [012]02?[01]111?20011020100[01]00010000000110021101000?0011011?1001011?1?00110 $101 ? 000 ? 30000110111100000 ? 120001[01] 1 ? 011 ? 02100[01] 000001101 ? ? 10 ? 10000 ? ? 0 ? 0010$ ?1??0??00000110000010000110?0001001100200?0?000000000101[12]01000[01]11000100 $10 ? 0000000000 ? 0020 ? 00 ? 100000000 ? 1000010 ? 0[01] 0100 ? ? 00 ? ? 1000 ? 11 ? 0 ? 1000000 ? 0 ? ? 1 ?$

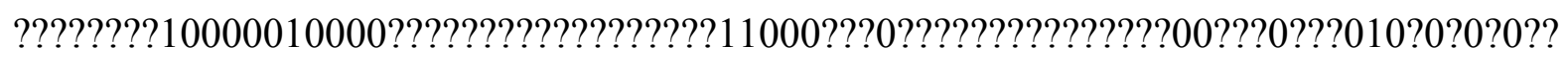
???0?0110?0000??0110??00????0?0??0?0?0??????0 
M._superciliousus

[012]02?1[12]11020011?20100100010000000110021101000?0011011?1001011?1?001101? 10001030000??01111?0000??????0?0?012?02?10000??11101??10?10000??0?0010????0??? 000????0000?0000110?00?00011?0200?0?000000000101101000?1100000010?000000???0? 0020000?100000000300111111010100???????00????????000??0??001??0????????????????? ???????????????????1??????????????????????00?0?0????100010?0?0?1???011000100????10 ??00????0?0?????????????0

M._casamequelai 0?2?1??10?0011?20?0010?010??00?????02?101001?0??1?1??????0?????0?1101????010?00 00????????????????????0?01??0??10??????1101??11?1?0??????0010????????0?????????0??

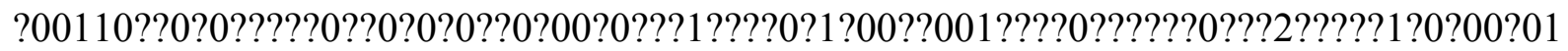
???1111110?0?00???????00??????????0?0???????????????????????????????????????????? ????????????????????????????????1?0000?0???????????????????????00??????0?0???????? $? ? ? 0$

C. araucaniensis 002012?102001112010010001000000011002110100000?1101??10010[01]1?1?000100?1?00 1030000????????0000????????0?012?0?01000???11101??10?1001???0?0010?[01]2?00??00? ??0?0?0010000110?00000011?0??0[01]0?00?000?00???1?1000?1?000?0010?000000???0?0 020000???00000003111111110?1?00????0??00????????000000??001?00??????????????????

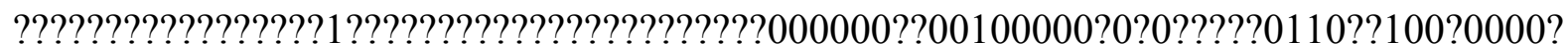
??000???0?0?0000?0???00?0 
C._suevicus

0?2012?10???11??01?0100010?000001?00????????????????????????????00[12]0??1 $2 ? 01030$ 000?????????????????????0?[12]?0??1?????011101??11??1??????0?0010?02?0???0?0010??

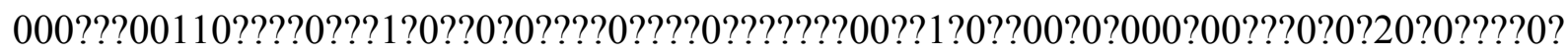
00000???11?11?0?1?00????0??00????????000??0??????0??????1???????????0??10000001? ??????1?????????????????????????????????????0?0?0??????????????????????00??????0???? ????????0

D._maximus 001?12?1????11??0??010?0???00?001???????????????????????????????01?0?????01??0000 ????????????????????????2?0??1??????1?00???1??1??????0?0011????????????????000??00 011?????????1?0????0????0????0????????????00???????????00???0?0????00?????0000???1 ?1????011100????0??0???????????????????????????????????????????????????????????????? ???????????????????????0?????????????????????????????0?????00???????????0?????????

D._andiniensis 001????1020011?200001000100000001?002?10100?00??1?1?????01]0???1?00?100?1?001 0?0000????????????????????0?012?0??10?????11001??1??1?01???010011112?0???00001?? 0?00??000110?00?00??1?0??0?0????0???00???[01]?1?0001?00??00???000?0????0???2000? ?1????0001?111111110?1?00????0??00????????000?00???????0??????1?????????????????? ????????????????????????????????????00?0??0??0000??0?0?????????????0???00???000???0 ?0000????????010

Rhabdognathus 202??????200??11100010011011010011012110101[01]01112011?1011010?1?11?202?????? 


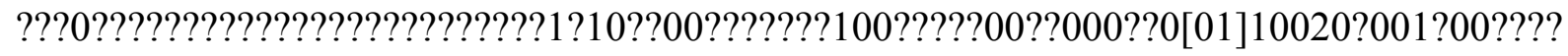
?1?????0?01[01]21000?0??1?000000????0??00?1010010??01?1000001?0000??????0???000 ???112?1????10??00000000?11?????0000111?0???0000000?????????????????????????????? ????????????????????????????????????0?0000010010100???????????????????????????00??? ?0?00?000?0???0?00

\section{Sokotosuchus}

2?2??21112??10????001001???101001?012?1??????1112?11?1?11??0???1?1?0?????????01? ?????????????????????????1?0???????????1???????0????????0?10????????0??????????????0 ?????????????1?????????0????????0??????????????1+??????????0???????????2??000?????0 ??001?0?11???????????????????????????????????????????????????????????????????????? ?????????????????????????????????????????????????????????????????????????????????

\section{Dyrosaurus}

202?12?102?010?11??010011??101001?012?10101[01]?1112011?1011?10?101112021???00 ?3?000??????????00???????????1?10??00???????10??????00???00??0010020?0???0??????1 000?00001?0100?????1?0?00?0????00000010?0??000?1??00?001??000000???0?0?0??00?11 201000?10??000000?0??1????0010011100???00000?0?001?????????????????????????????

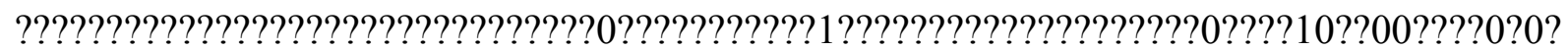
?????????????

Hyposaurus ?02?12?102??1???????1????0?101??????2????????1?12011?1019?10?1?1??2?????0???3?000

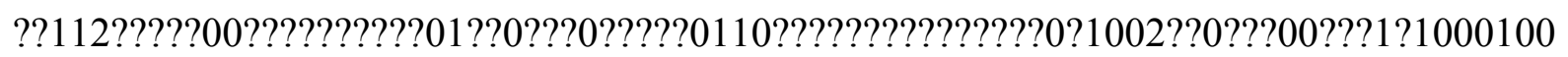
?0????00???0?1??????0?000000?00???0?????????0???01?????0?????0???????????2???????? 
???0???0????1????00??0?1??????000??00????????????????????????????????????????????? ???????????????????????????????01?????????????????????????1[01]??00????????????????? $? ? ? ?$

Pholidosaurus

212?121102??1??1110?10011??0010001012110101?01112?11?101??10?100?121[12]???0?? ?3?0????1?2???0??0??200????????0??0????????1?0??1?110?????0?00100???????00?????? 000?0000102?100????1?0000?0???000?00?10?0?10??01?110?0010???0??????0???0???0?10 ??1????1???0?0001?0?00???????00??????????0?????????????????1??????????????????????? ????????????????????????????????????????????????????????????????????????????????????? ???????0

Sarcosuchus

203?12?10200101?100010011001010001012?10101101?12?1??10100?0?100?121211??0003 10101?112????[01]00?1200?00??010[01]0??00[01]00??0?101??121100??00000010010?1??? $00 ? ? ? 110 ? 0[012] 11010[01] 021[01] 00 ? 0001 ? 000000 ? 000000 ? 00 ? 01001000 ? 1 ? 120 ? 0010 ? 000$ 00000?0?0100000?10001111?100?0?000100?10????00110?1100?0?0001000?001?????????1 0000?100?????????????????????0??????????????????????0000?0010?1?0000?00100?000110 00000?00?0???00????0?000000?0???0?00

Terminonaris

202?[01]2?1020010?11??01001???1010001012?1010[01]1??????11?1010??0??0??12[01][12 ]11?000?3100011112??00000?1200?10??0?010210?100?001101??1??10??0??0?0010????1? ??000011100?0???101[01]2110?????1?0000?0?0000?0000?0?00?0?0?11120?00?0??00???00 ?0?0100?00?10201111?1?0?0?00?100??00???00?10111?000100000000001???????????????? 
??????????????????????????????????????????????????????????????????????????????0???1

$10 ? ? 00 ? ? ? ? ? ? 0 ? ? ? ? ? ? ? ? ? ? 0 ? 00$

\section{Rugosuchus}

203??[12]?1?20?00??1??0110111????00010[01]2110?010?1112?11?1010000?1?0??21??1?0 010202???????????????2?[12]0??0?[03]0?000???0?????01?01??1?1000?0?00??0100?1?1??? 00???100?0?1?100??2???0?10???10???110000?0?0????0?100001?100?0010?000020???0?0? 00000?1?0??000?000?00000100?01????0?????????????0111???????????????????????????? ??????????????????????????????????????????????????1?????????????????????????1???00? ????????????????????

\section{Argochampsa}

202?121112001011???110[01]101?0010001012110?022??112?11?10110?0?1?0?1200??????

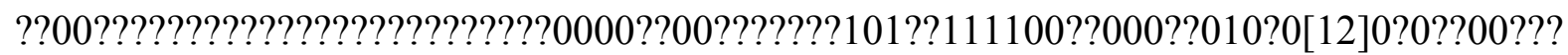
????????0001021?01?1??1?00?020????0???0???1?010?????1000??10?0?0??????0?0?00000? 0??000?0?10??0?000100??1???????1001?0????0000??0???????????????????????????????? ????????????????????????????????????????????0?????????????????????????????0?????0??? ?????????????

\section{Lavocatchampsa}

1?0???????0?00??????1??????????????2????????????????????????????1?????????2?0?0?? ???????????????????0??1?1??????????11????????0???????0??1?????????????00???0111011? ?????1???1?0????0?01?2100???????????????????????????????????????????0????????????? ???????0????0?0????????????1?????????????????????????????????????????????????????? ??????????????0?????????????0?01???0????????????0?0?00100?0?0????0????0?????? 


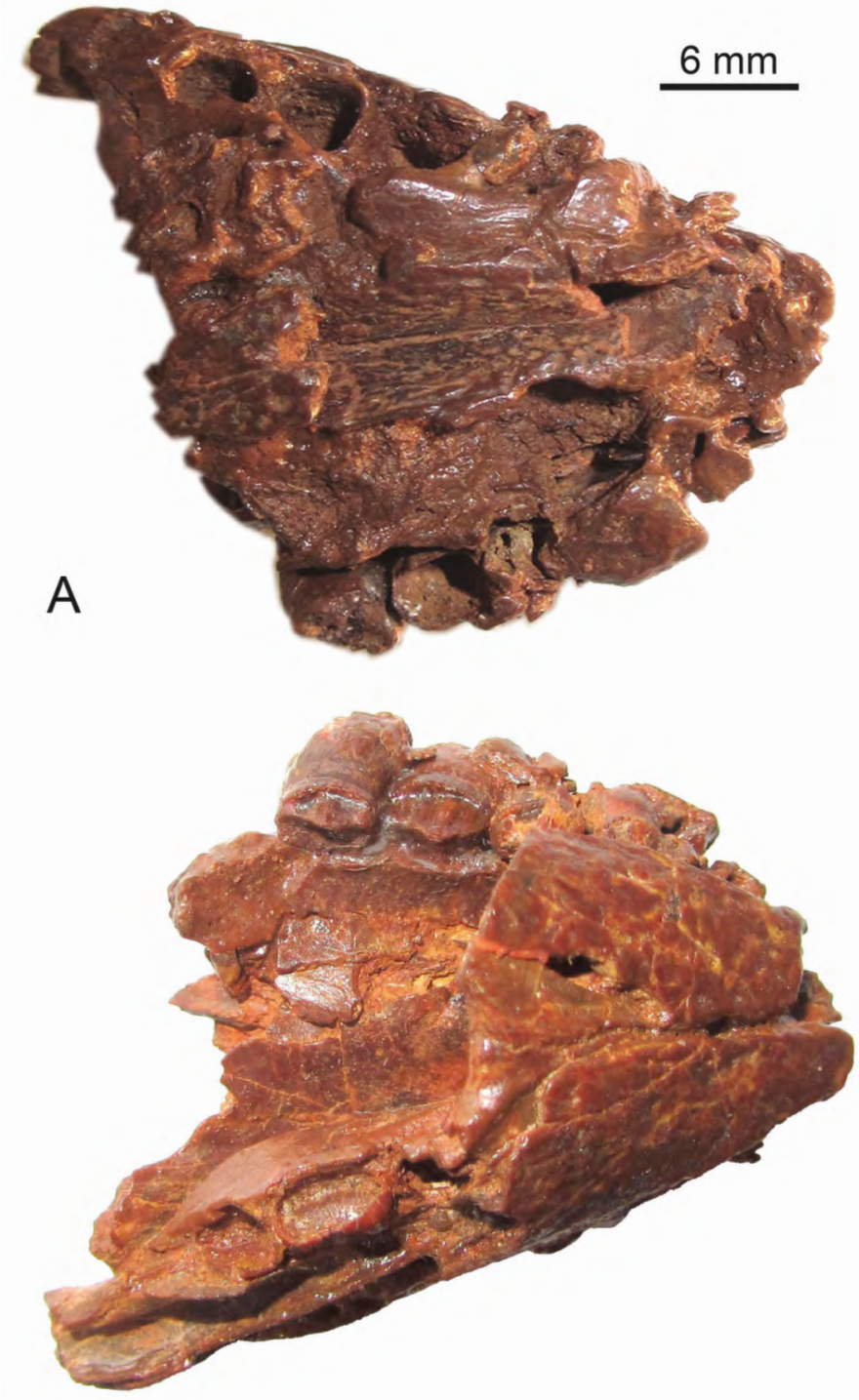

B

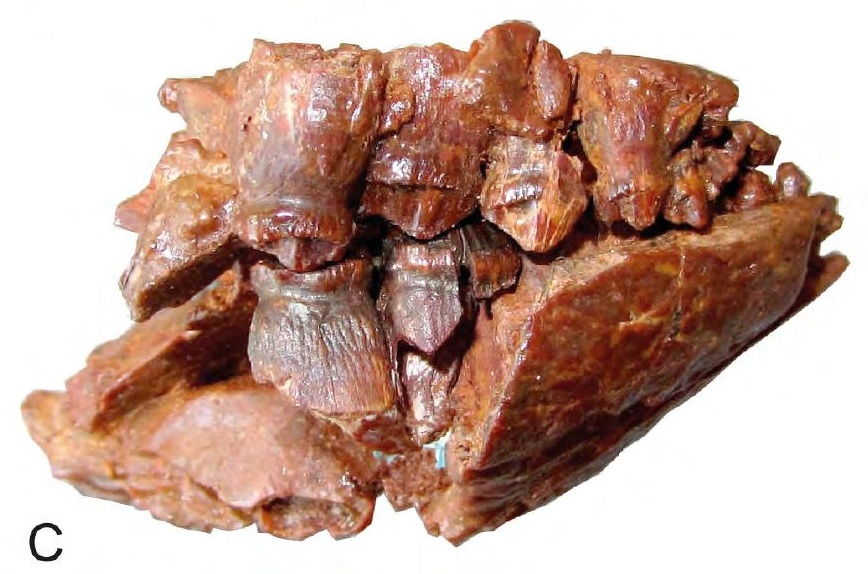


A

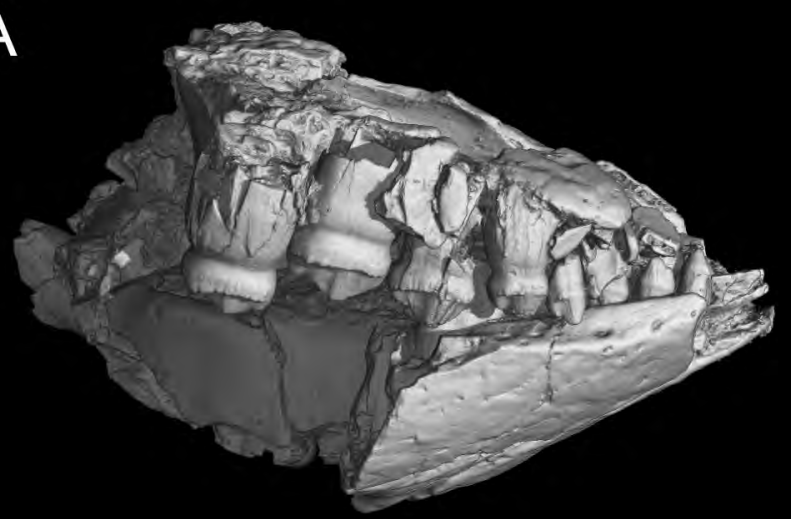

C

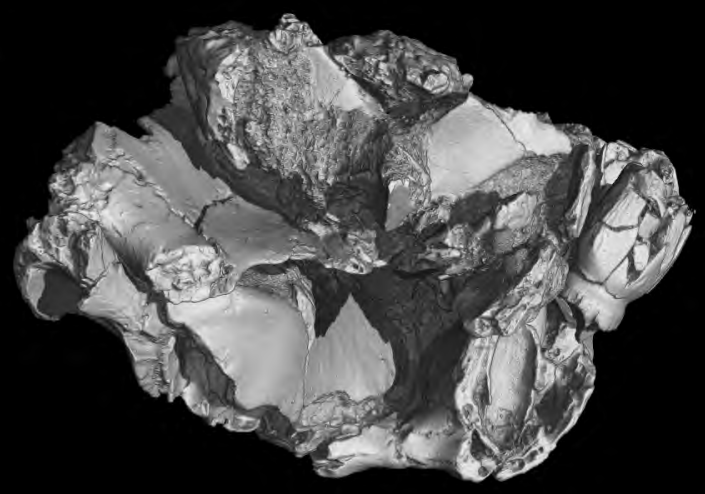

B

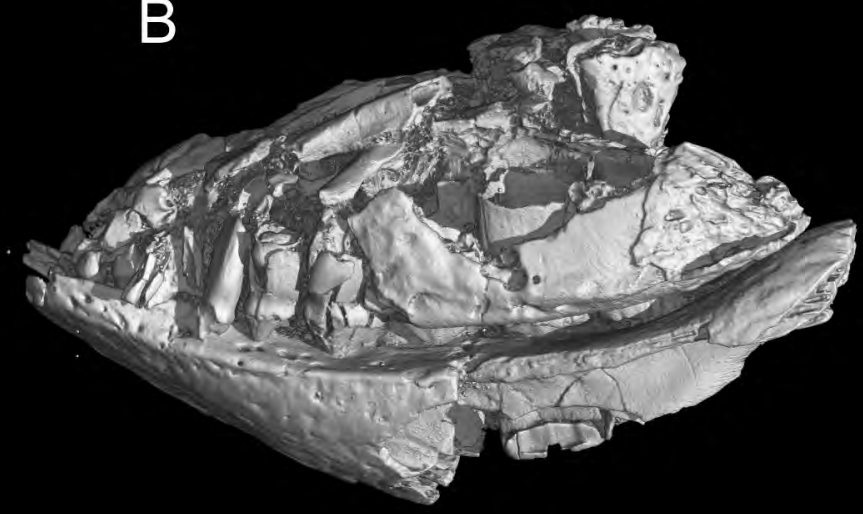

D entors

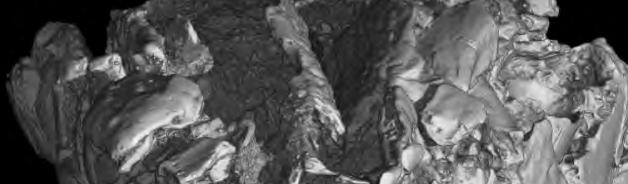
ation 214

$6 \mathrm{~mm}$
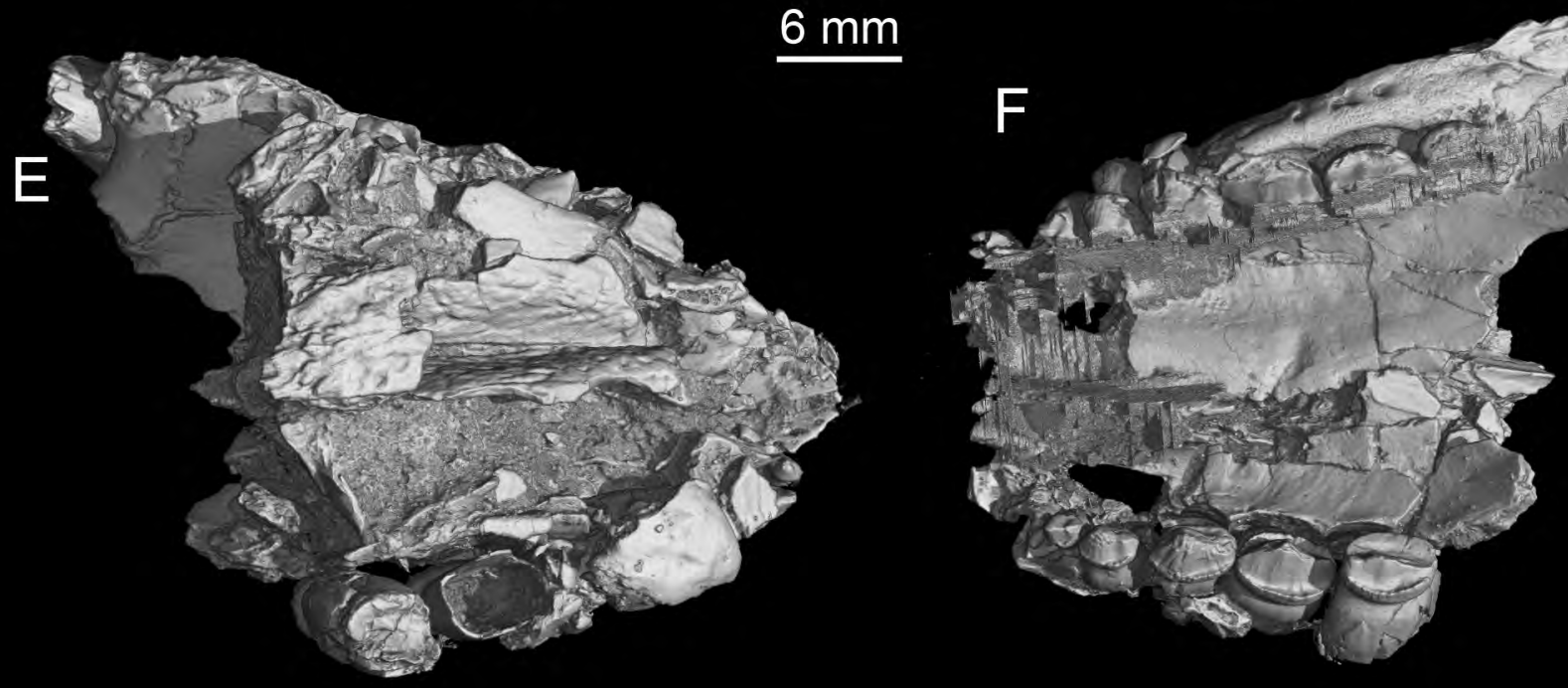

$\mathrm{H}$

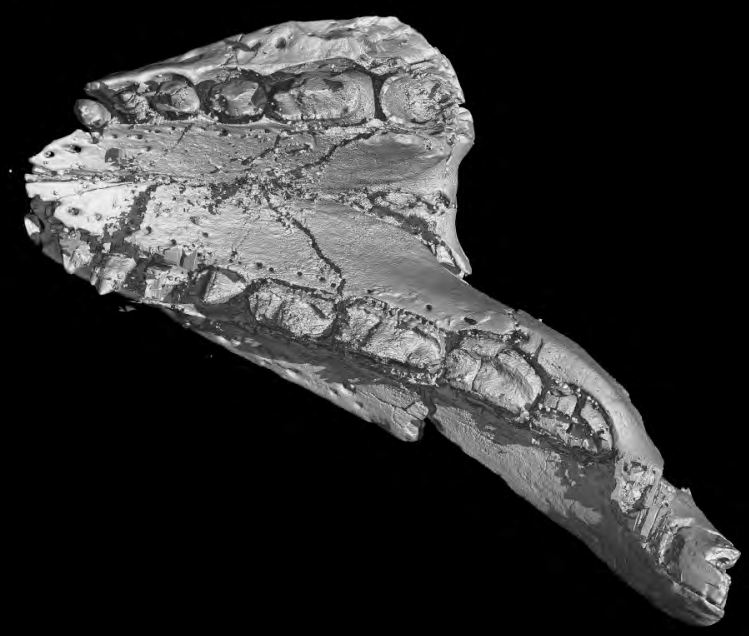



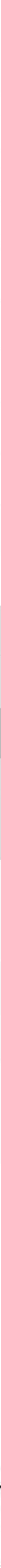


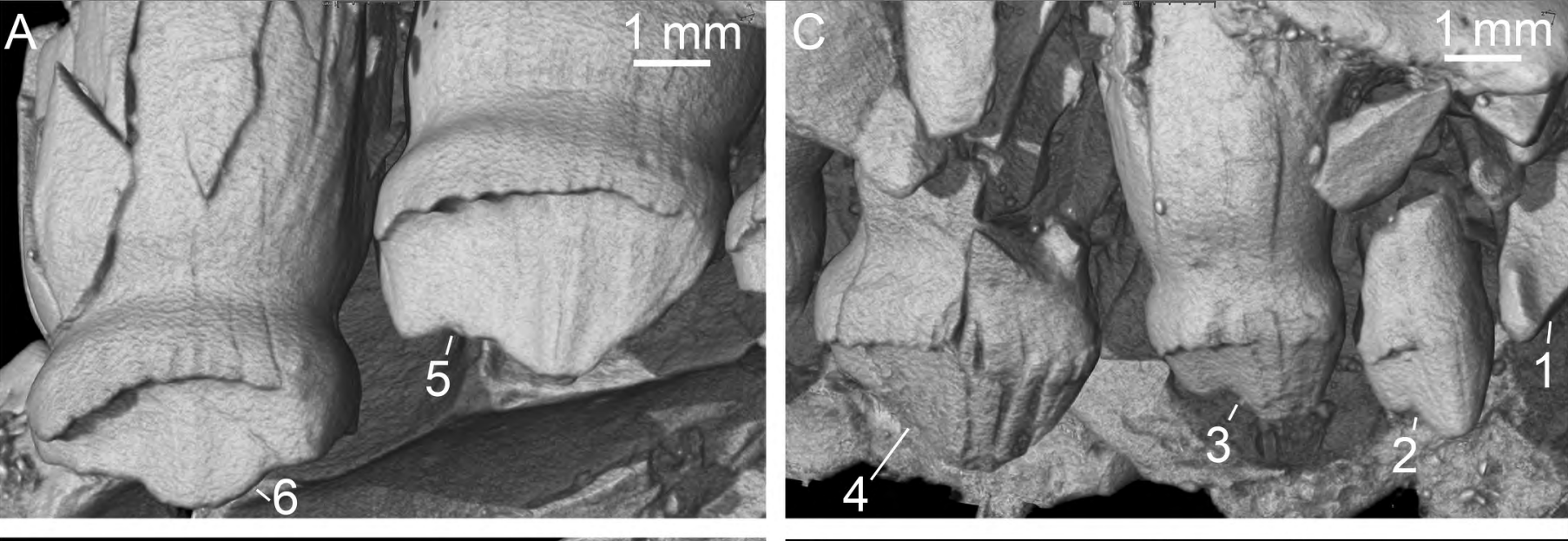

B
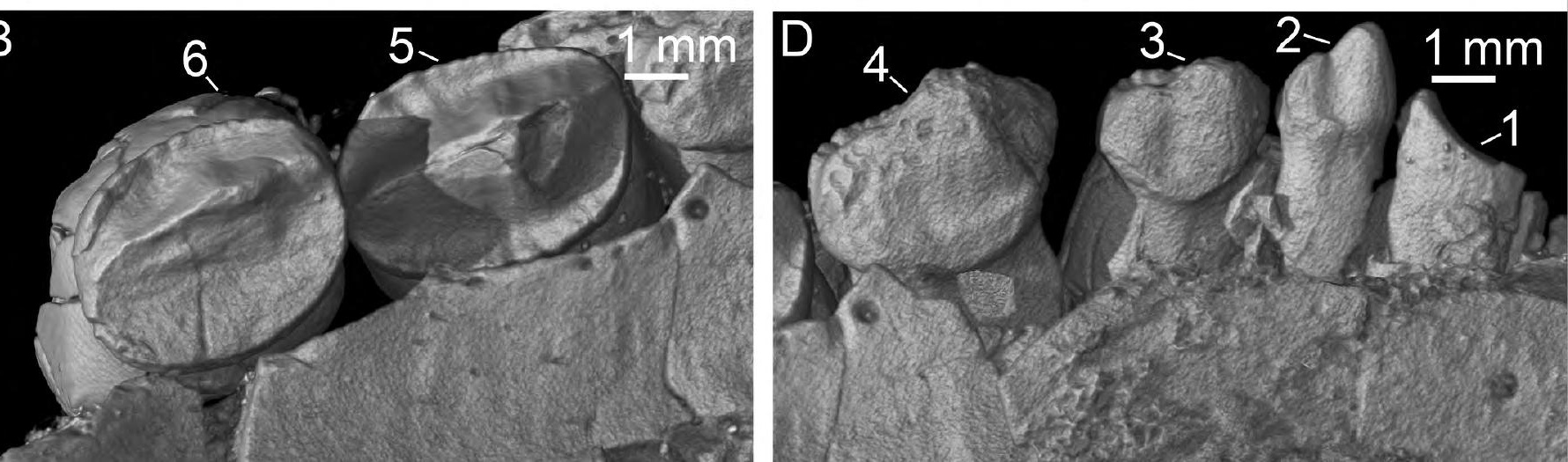


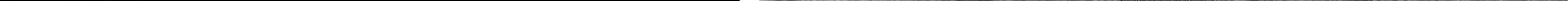




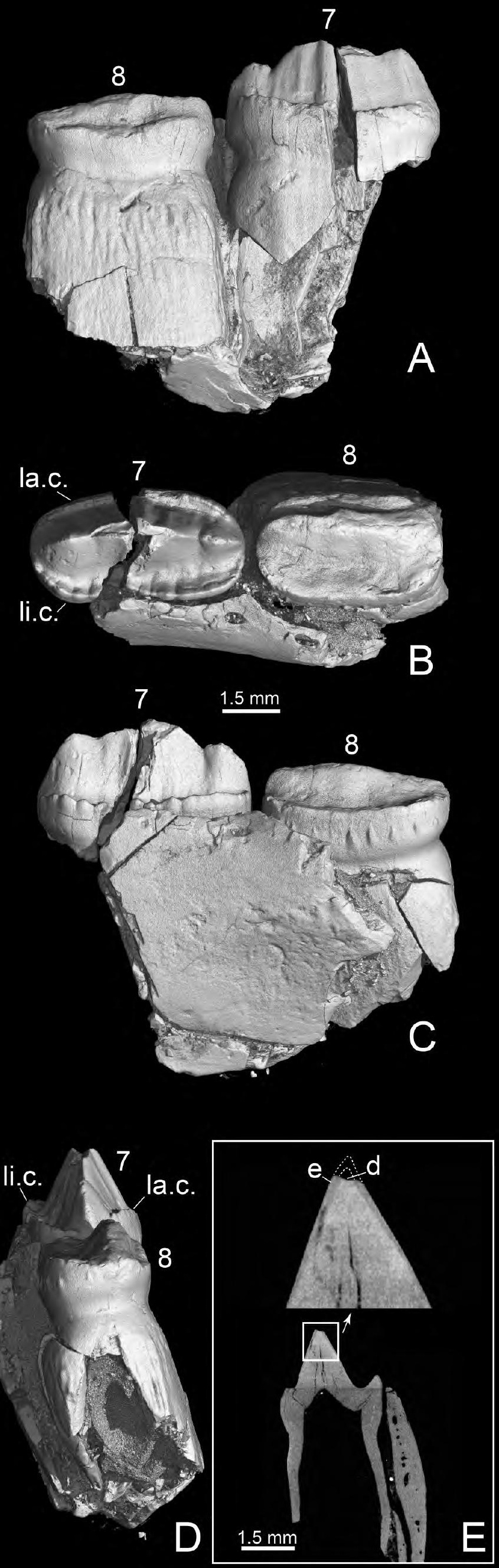




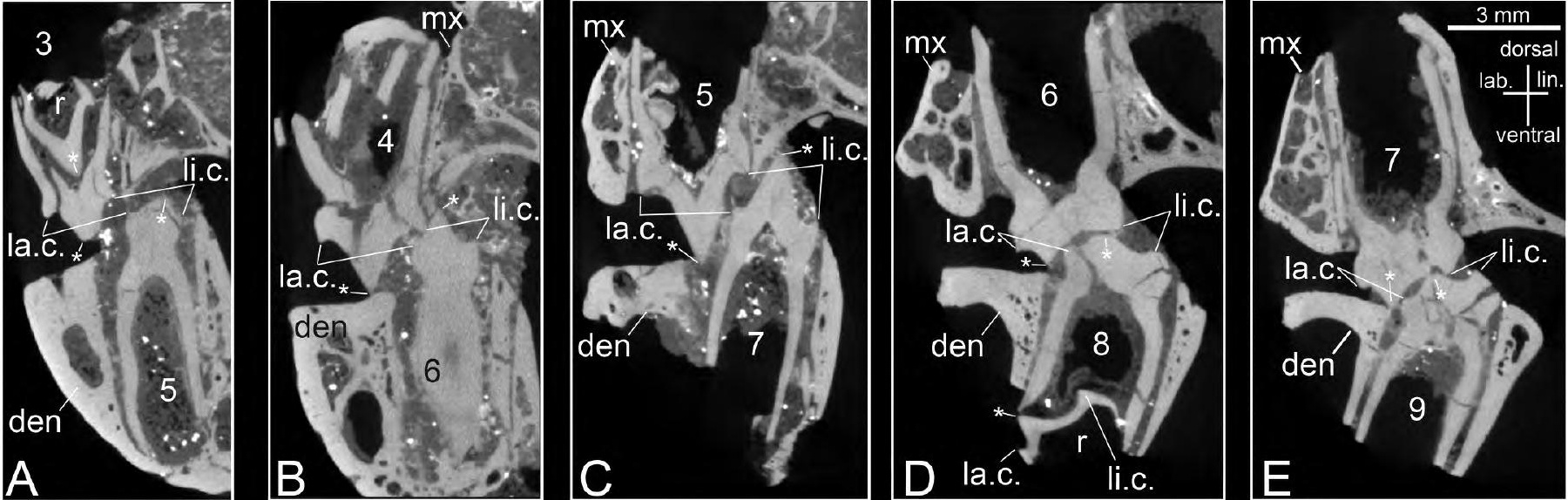


A 


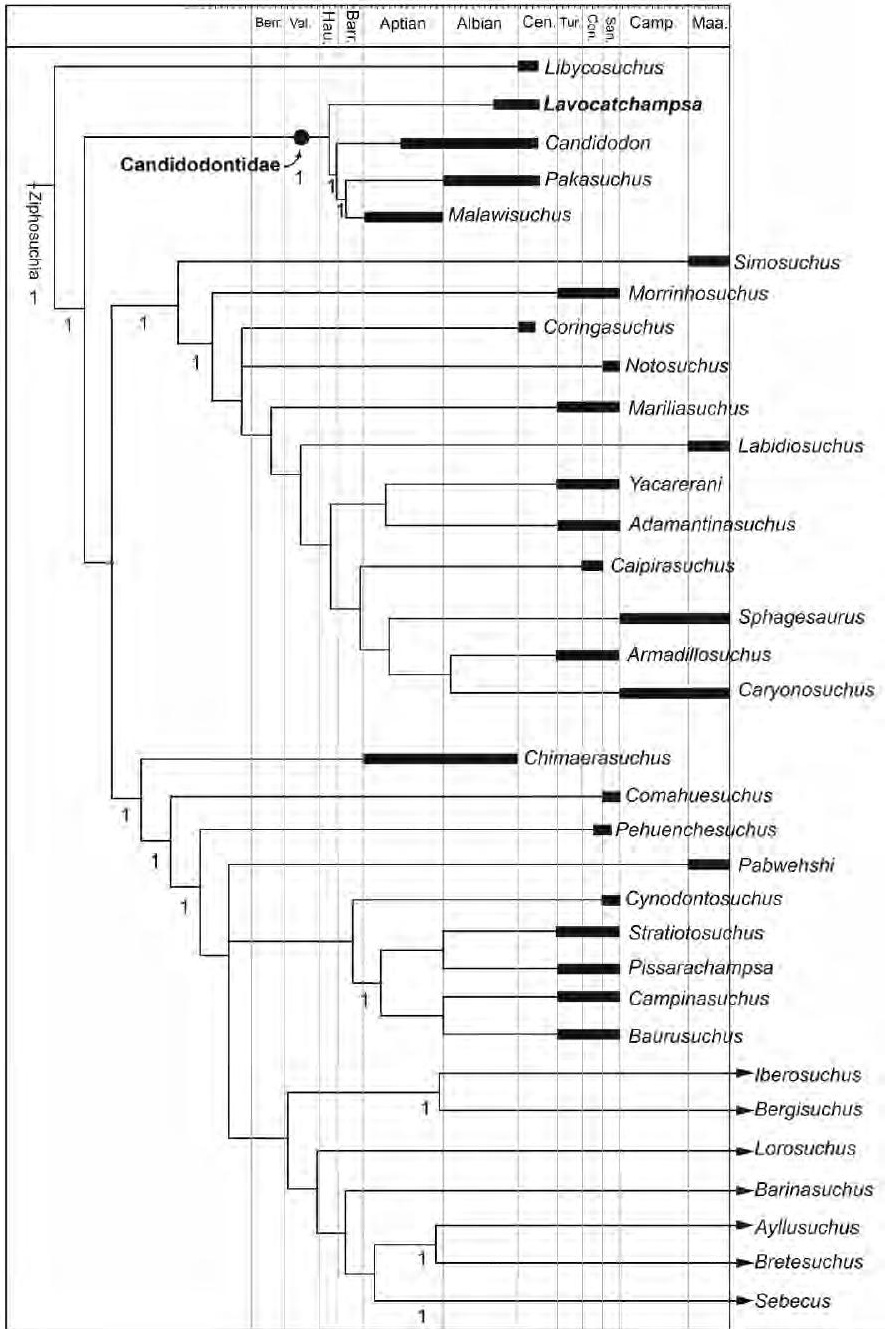

